\title{
واقع رأس المال الاجتماعي ومحدداته في الوطن العربيي
}

\section{Social Capital and its Determinants in the Arab Region}

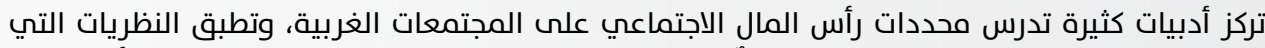

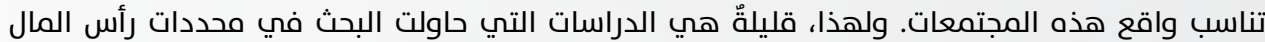

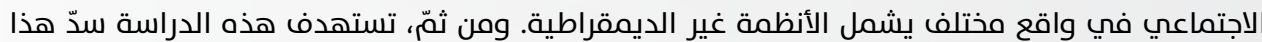

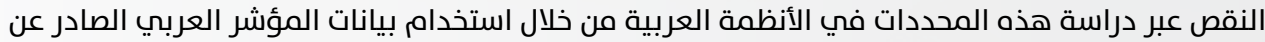

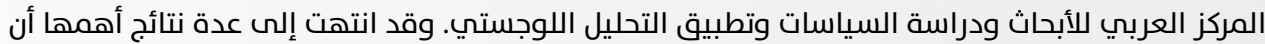

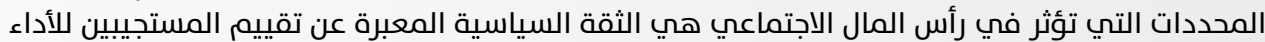

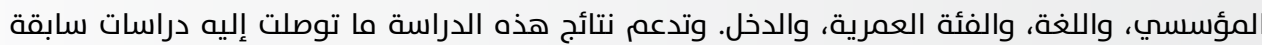

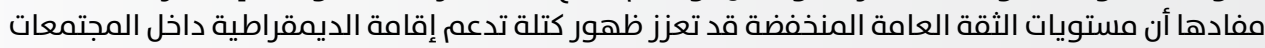

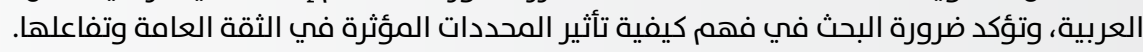

كلمات مفتاحية: رأس المال الاجتماعي،، الثقة العامة، أداء المؤسسات العامة، المؤشر العربي،، الربيع

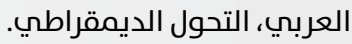

The literature on the determinants of social capital on Western societies focuses on theories that fit their realities. There are few studies that investigate the determinants of social capital in different environments, including in non-democratic regimes. This study aims to fill this gap by studying these determinants in Arab countries. This study employs a Logit Model and uses the Arab Opinion Index data published by the Arab Center for Research and Policy Studies. The study makes several conclusions, the most important of which are that the determinants affecting social capital are political confidence (expressed through respondents' assessment of institutional performance), language, age group, and income. The results of this study reinforced the results of previous work that found that low levels of public confidence may promote the emergence of a democracy-supporting bloc within Arab societies. However, there is a need to better understand how determinants interact with and impact public confidence.

Keywords: Social Capital, Public Trust, Performance of Public Institutions, Arab Index, Arab Spring, Democratic Transition.

" باحث مهتم بقضايا التنمية في الوطن العربي، وبخاصة قضايا التعليم والبطالة والعدالة الاجتماعية، حاصل على شهادة الماجستير في اقتصاديات التنمية.

Researcher interested in development issues in the Arab world, in particular, education, unemployment and social justice. Holds a master's degree in development economics.

Email: anas.alqaisiya@dohainstitute.edu.qa 
تُعد دراسة القضايا المتعلقة برأس المال الاجتماعي ملهمة للعديد من الباحثين الاقتصاديين في العقود الأخيرة، كما

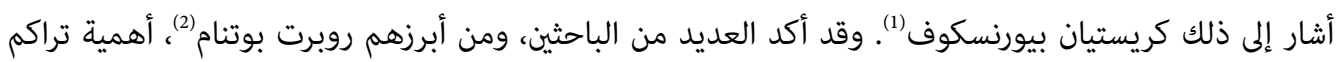

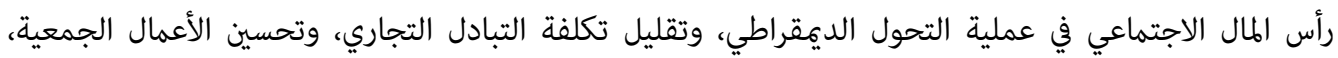

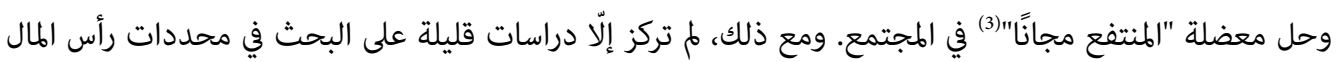

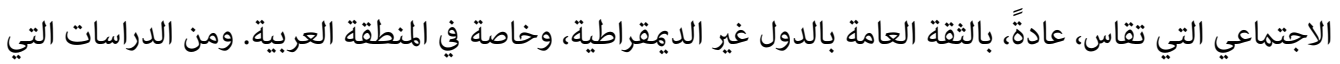

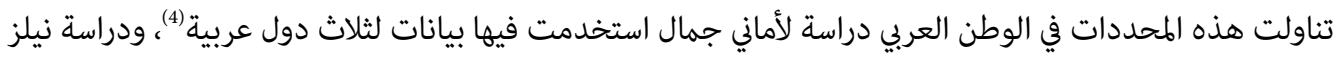

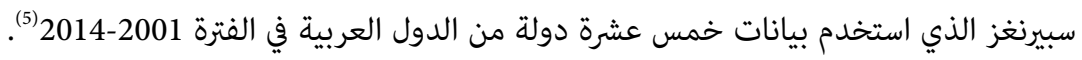

وتطمح هذه الدراسة إلى أن تضيف إلى هذه الأدبيات؛ لكونها تحاول البحث في محددات رأس المال الاجتماعي في الوطن العربي من خلال مصدر بيانات وفترة زمنية مختلفة عن سابقاتها، وهي تشمل اثنتي عشرة دولة عربية خلال

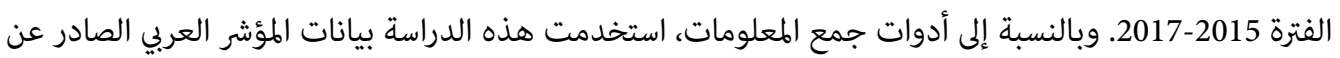

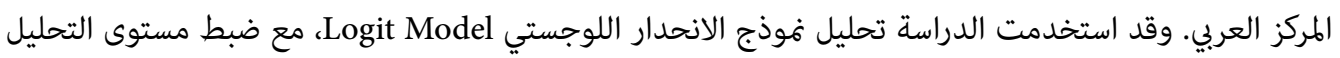
في واقع المحافظات والمديريات بمختلف الدول العربية (6).

تعرض الدراسة في الجزء الأول الإطار النظري والمفاهيمي، وأهم الأدبيات التي أطّرت رأس المال الاجتماعي، وكيفية قياسه، والقضايا الأخلاقية فيه. ويهتم الجزء الثاني منها بعرض خلفية وصفية متعلقة بالبيانات المستخدمة في الإطار

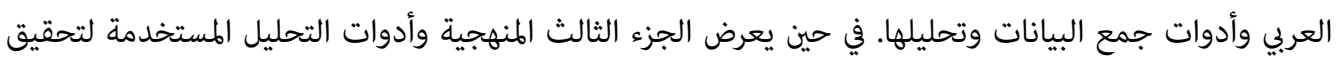

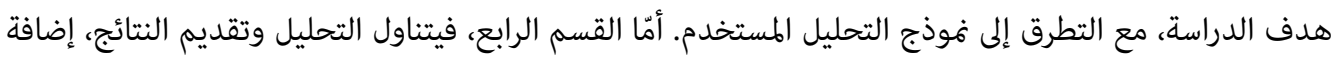

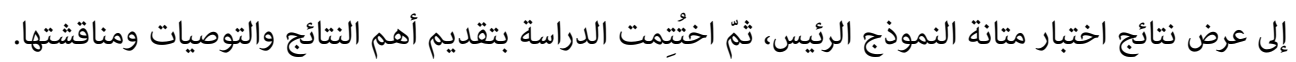

\section{أولًا: الإطار النظري والمفاهيمي}

أصبح لرأس المال الاجتماعي دور في تفسير العديد من الظواهر الاجتماعية - الاقتصادية التي شغلت اهتمام باحثي

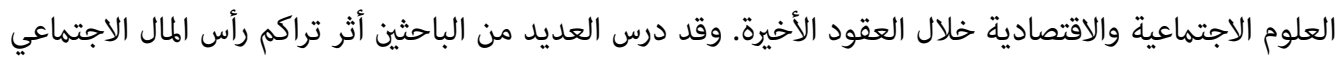

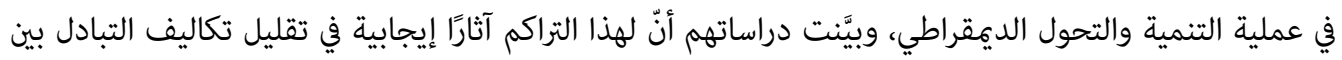

1 Christian Bjørnskov, "Determinants of Generalized Trust: A Cross-country Comparison," Public Choice, vol. 130, no. 1-2 (2007), pp. 1-21.

2 Robert D. Putnam, Robert Leonardi \& Raffaella Nanetti, Making Democracy Work: Civic Traditions in Modern Italy (Princeton: Princeton University Press, 1993).

3

مقابل لها.

4 Amaney Jamal, "When is Social Trust a Desirable Outcome?: Examining Levels of Trust in the Arab World," Comparative Political Studies, vol. 40, no. 11 (2007), pp. 1328-1349.

5 Niels Spierings, "Social Trust in the Middle East and North Africa: The Context-Dependent Impact of Citizens' Socio-Economic and Religious Characteristics," European Sociological Review, vol. 35, no. 6 (2019), pp. 894-911.

6 أُضيف إلى التحليل متغير يضبط التحليل على مستوى المحافظة داخل الدول العربية لضبط أثر العوامل التي لا تتغير عبر الزمن داخل المحافظة 
الأفراد، وزيادة قدرة المجتمع على القيام بالأعمال الجمعية Collective Action، والحد من معضلة المنتفع مجانًا،

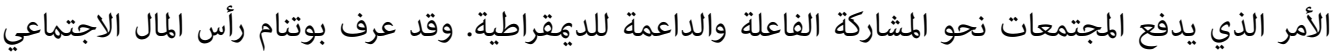
بأنه "خصائص النظام الاجتماعي، كالثقة والعادات والشبكات الاجتماعية، التي تزيد المجتمع كفاءةً من خلال

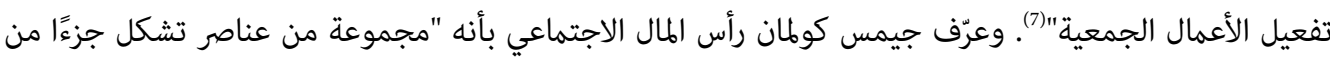

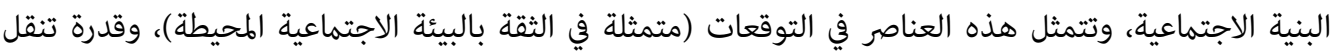

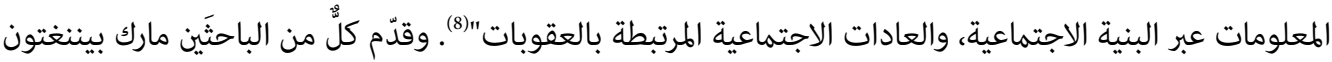

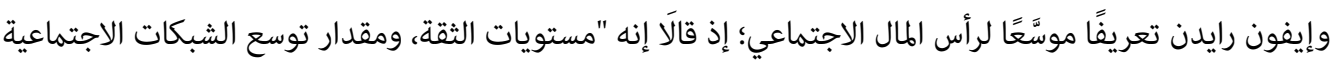

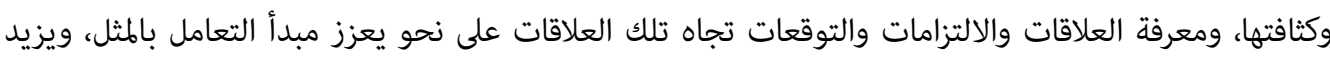
الوعي بالمحيط المحلي، ويفعٌل استخدام العقوبات لمحاسبة عملية الانتفاع مجانًا"(9).

ويؤكد فرانسيس فوكوياما أن التشارك في القيم والأعراف لا ينتج رأس المال الاجتماعي؛ لأن الأعراف من الممكن أن تكون

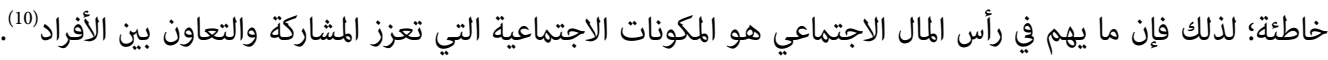

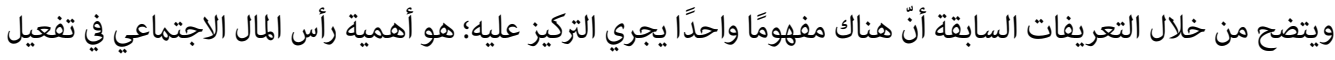

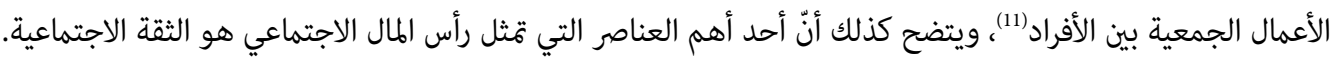
وللثقة الاجتماعية تعريفات عدة، لعل أهمها التعريف الذي يفرق بين الثقة العامة Generalized Trust، والثقة

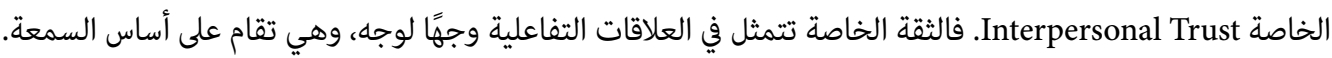
في حين أن الثقة العامة موجّهة إلى الغرباء، وهي تُبنى على مشاركة المجتمع مجموعة من القيم التي تضع تصورات

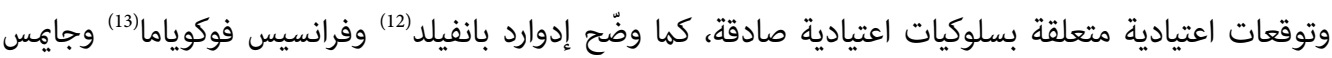
سكوت(14). وقد استهدف العديد من الباحثين في دراساتهم الثقة العامة، باستخدام البيانات المتوافرة من السؤال الآتي:

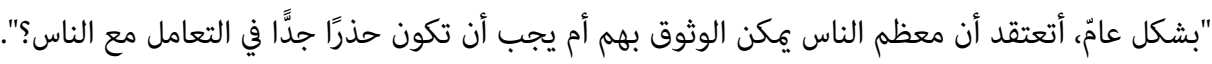

تتوفر هذه البيانات في العديد من دول العالم التي تُستهدَف من قبل مسح القيم العالمية World Values Survey, WVS،

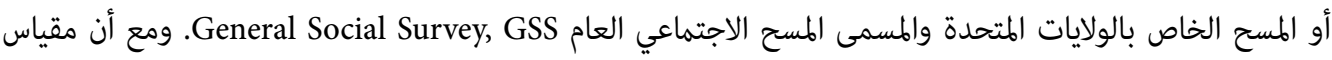

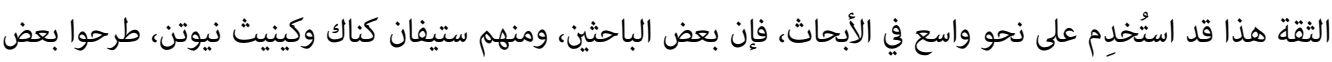

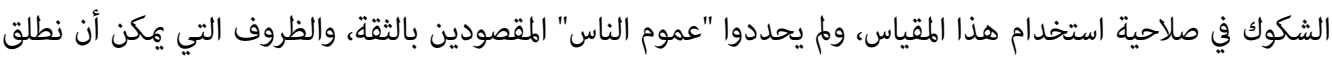

\footnotetext{
7 Putnam, p. 2.

8 James S. Coleman, "Social Capital in the Creation of Human Capital," American Journal of Sociology, vol. 94 (1988), p. 119.

9 Mark Pennington \& Yvonne Rydin, "Researching Social Capital in Local Environmental Policy Contexts," Policy \& Politics, vol. 28, no. 2 (2000), pp. 233-249.

10 Francis Fukuyama, "Social Capital: The Tanner Lectures on Human Values," Brasenose College, Oxford, vol. 12 (1997), pp. 335-484.

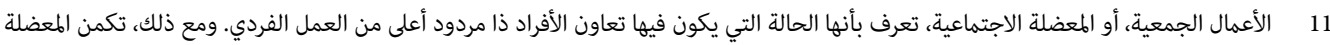

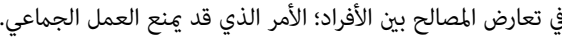

12 Edward C. Banfield, The Moral Basis of a Backward Society (New York: Free Press, 1958).

13 Francis Fukuyama, Trust: The Social Virtues and the Creation of Prosperity (New York: Free press, 1995).

14 James Scott, Seeing like a State: How Certain Schemes to Improve the Human Condition Have Failed (United States of America: Yale University Press, 2020).
} 
عليها الثقة بالناس أو عدم الثقة بهم (15). ومع ذلك، أكد غلايسر وآخرون، من خلال إجراء تجربة على مقياس الثقة العامة إزاء مجموعة من خريجي جامعة هارفرد، وجود اختلاف في مفهوم الثقة Trust والموثوقية Trustworthiness؛ فالثقة تعتمد على قرار الفرد في أن يثق بشخص آخر تحت ظرف معين وفي وقت معين، في حين تتمثل الموثوقية في توقّع الفرد من شخص آخر غريب أن يقوم بالعمل الصحيح بحسب الأعراف الموجودة(16.). لذلك، فإن سؤال الثقة العامة يصلح لقياس رأس المال الاجتماعي على صعيد الجماعات، ويعبّر عن توجه المجتمع نحو تفعيل الأعمال الجمعية، وهذه الدراسة تعتمد على مقياس الثقة العامة لدراسة محددات هذه الثقة.

يُعد كتاب بوتنام من أبرز المراجع التي أسَّست لنظرية رأس المال الاجتماعي وأهميته في عملية التحول الديمقراطي؛ من خلال دراسته المناطق المختلفة من إيطاليا (شمالًا وجنوبًا)(17). فقد وجد أن المؤسسات السياسية الإيطالية في مختلف المناطق تتباين في أدائها تبعًا لرأس المال الاجتماعي؛ إذ إنّ المناطق الشمالية ذات رأس المال الاجتماعي الأعلى

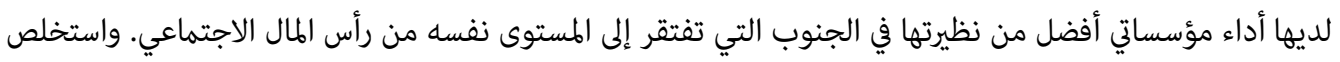
بوتنام أن فكرة التغيير المؤسساتي ستؤثر تدريجيَّا في تطوير رأس المال الاجتماعي، وأكد أهمية القوانين والقواعد، الموجودة من جهة المؤسسات، في تراكم رأس المال الاجتماعي، والتحكم في تفاعل القوى الاجتماعية والسياسية المختلفة. وقد دعم نيوتن هذه النتيجة فأوضح بدايةً، من خلال استخدام نظرية المجتمع المدني، أن العلاقة بين الثقة الاجتماعية والثقة السياسية غير واضحة قامًا من حيث السببية، إلا أنه أكد وجود تأثير من الأعلى إلى الأدنى في المستوى الجمعي من خلال تأثير أداء المؤسسات الفعال في إنشاء ظروف اجتماعية تعزز مدنية المجتمع، وترفع مستويات رأس آس الهال الاجتماعي فيه (18). كذلك، أكد لويجي قوسو وآخرون، في دراسة تلخص الأدبيات الخاصة بالثقة الاجتماعية، أن للمؤسسات غير الرسمية التي أطلقوا عليها "الثقافة" أهمية المؤسسات الرسمية نفسها في تفسير الازدهار والتنمية، وأن للثقة العامة دورًا أساسيَّا في صياغة الثقافة الموجودة في المجتمع، وأن القوانين تسهم بفاعلية في تشكيل الثقافة الاجتماعية (19.) ولهذا، فإن تأثير المؤسسات في رفع مستوى الثقة الاجتماعية من خلال السياسات العامة أمرٌ أكدته العديد من الدراسات، موضحة أن تأثير المؤسسات في الثقة العامة يتأتى من خلال التعليم وجودة المؤسسات، كما بيّن ذلك كلّ من ديبا ناريان(20)، وستيفن كناك وبول زاك (21)، وأفيناش ديكست (22)، وكريستيان بيورنسكوف (23.).

15 Stephen Knack, "Trust, Associational Life, and Economic Performance," The Contribution of Human and Social Capital to Sustained Economic Growth and well-being (2001), pp. 172-202; Kenneth Newton, "Trust, Social Capital, Civil Society, and Democracy," International Political Science Review, vol. 22, no. 2 (2001), pp. 201-214.

16 Edward L. Glaeser et al., "Measuring Trust," The Quarterly Journal of Economics, vol. 115, no. 3 (2000), pp. 811-846.

17 Putnam, p. 2.

18 Newton, p. 3.

19 Luigi Guiso, Paola Sapienza \& Luigi Zingales, "Corporate Culture, Societal Culture, and Institutions," American Economic Review, vol. 105, no. 5 (2015), pp. 39-336.

20 Deepa Narayan, Bonds and Bridges: Social Capital and Poverty (Washington DC: World Bank, 1999).

21 Stephen Knack \& Paul J. Zak, "Building Trust: Public Policy, Interpersonal Trust, and Economic Development," Supreme Court Economic Review, vol. 10 (2003), pp. 91-107.

22 Avinash K. Dixit, Lawlessness and Economics: Alternative Modes of Governance (Princeton: Princeton University Press, 2011).

23 Christian Bjørnskov, "How Does Social Trust Affect Economic Growth?" Southern Economic Journal, vol. 78, no. 4 (2012), pp. 1346-1368. 
اعتمدت العديد من الدراسات على بيانات مسح القيم العالمية لقياس أثر الثقة العامة في عملية التنمية وارتباطها

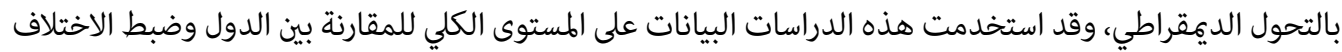

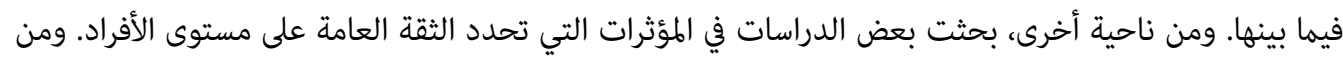
أهم هذه الدراسات دراسة ألبيرتو ألسينا وإلينا لافرارا التي استخدمت بيتهن بيانات GSS التي تقام في الولايات المتحدة على مستوى الأفراد خلال الفترة 1974-1994، من أجل دراسة محددات الثقة الاجتماعية، وخلصت الدراسة إلى إلى

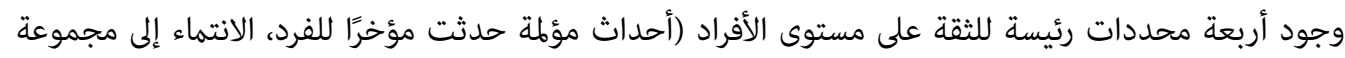

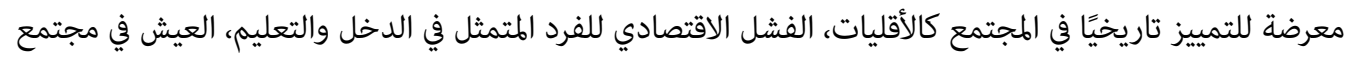

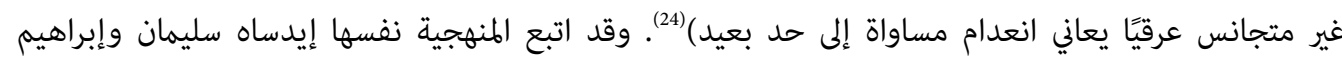

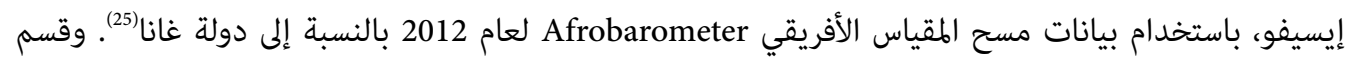

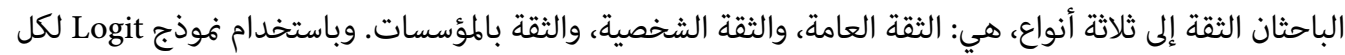
مقياس من هذه المقاييس، وجد الباحثان أن النوع الاجتماعي والعرق والتدين والتمثيل السياسي كلّها عوامل تؤثر في الثقة بالمؤسسات، في حين يؤثر العرق والدين فقط في الثقة العامة. كما وجدا أنّ لدى المسلمين وسكان المناطق وإنقان

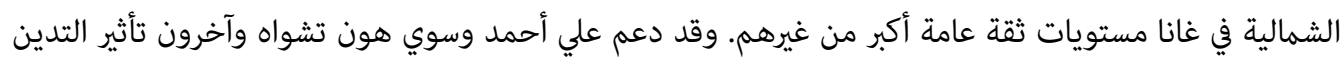
والانتماء الديني في مستويات الثقة العامة (26).

أما دراسة سيرغي غوريف ونيكيتا ملينغوف (27)، فهي إحدى الدراسات المثيرة للاهتمام؛ إذ استخدمت مقياسًا غير

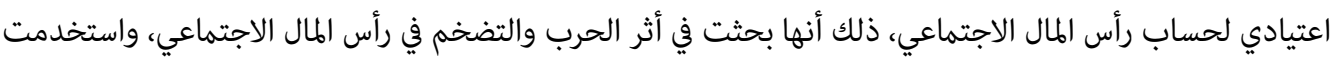
"غوغل" Google للبحث عن كلمات مفتاحية تعبّر عن تصرف اجتماعي إيجابي على مستوى المناطق المتأثرة بالنزاع

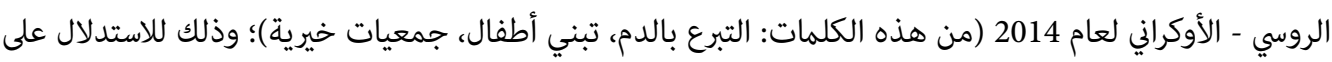

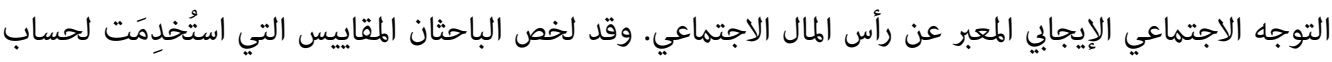

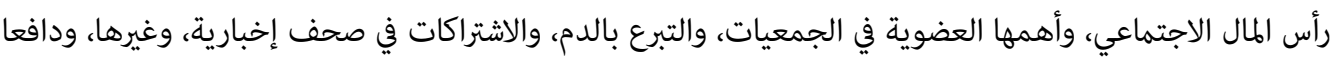

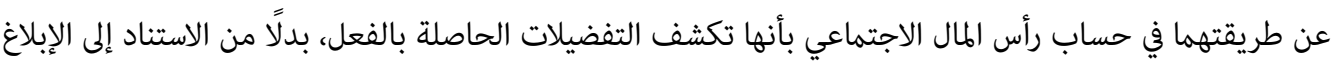

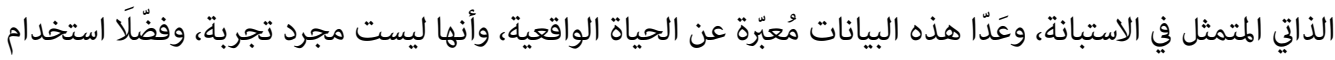
هذه البيانات نظرًا إلى توافرها بوتيرة عالية. ركزت معظم الدراسات التي ذُكِرَت سابقًا على دراسة الثقة الاجتماعية بالدول المتقدمة أو الديمقراطية، والتي لديها

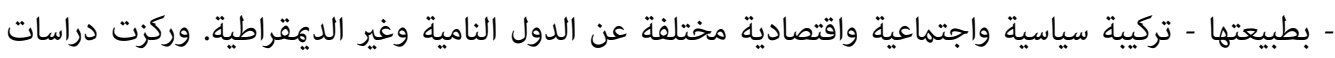

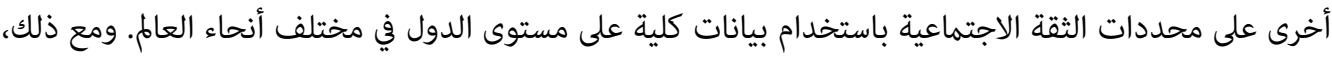

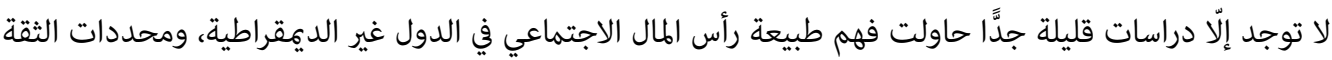

25 Iddisah Sulemana \& Ibrahim Issifu, "An Empirical Examination of the Determinants of Trust in Ghana," International Journal of Social Economics, vol. 42, no. 11 (2015), pp. 1005-1023.

26 Ali M. Ahmed, "Are Religious People more Prosocial?: A Quasi-experimental Study with Madrasah Pupils in a Rural Community in India," Journal for the Scientific Study of Religion, vol. 48, no. 2 (2009), pp. 368-374; Swee-Hoon Chuah, Reema Fahoum \& Robert Hoffmann, "Fractionalization and Trust in India: A Field-experiment," Economics Letters, vol. 119, no. 2 (2013), pp. $191-194$. 
الاجتماعية وكيفية عملها في هذه الدول. أما على مستوى الوطن العربي، فهناك دراستان ركزتا على دراسة الثقة؛ هما

$$
\text { دراستا سبيرنغز (28)، وجمال (29) }
$$

تعتمد هذه الدراسة على منهجية مقاربة للمقاربات المستخدمة في هاتين الدراستين، مع مراجعة النتائج ومقارنتها

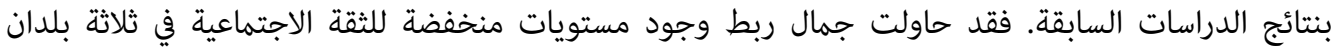
عربية (مصر، والمغرب، والأردن) بالأداء المؤسساتي الضعيف الناتج من الأنظمة غير الديمقراطية التي تحكم هذهاته البلدان، واستخدمت بيانات مسح القيم العالمية WVS خلال الفترة 1972-2006 (30. وأكدت الباحثة أن أن تقييم الأداء المؤسساتي في الأنظمة الديمقراطية وغير الديمقراطية يعمل بالطريقة ذاتها، ولكن بنتيجة مختلفة. فمن جهة أولى، تعبّر المؤسسات السياسية في الأنظمة الديمقراطية عن مصالح الأفراد واهتماماتهم، وتدافع عنها وتحميها؛ الأمر الذي جئه

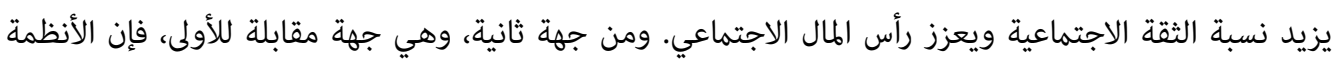

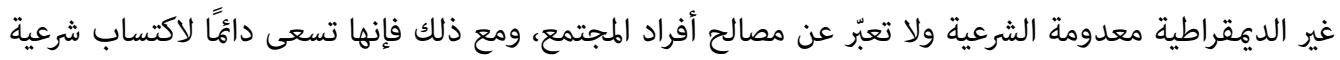
اجتماعية من خلال تقديم امتيازات معينة لبعض الفئات المجتمعية. وبناءً عليه، جادلت الباحثة بأن لدى الأشخاص إصناص المستفيدين من هذه الامتيازات مستويات ثقة أعلى بالمؤسسات السياسية التي تدافع عن مصالحهم؛ ما يزيد نسبة ثقتهم العامة. وعلى النقيض من ذلك، يشعر الأشخاص الذين يقيّمون أداء المؤسسات السياسية على أساس أنه تهأه ضعيف بأن هذه المؤسسات لا تحمي مصالحهم؛ ما يُضعف مستويات الثقة العامة لديهم (31). وأظهرت نتائج هذه الهن

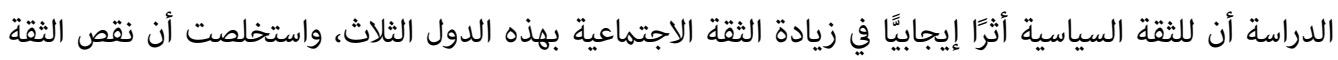
العامة في ظل الأنظمة غير الديمقراطية يعني أن الأفراد لا يمنحون هذه الأنظمة الشرعية التي يطلبها، وهو مؤشر إنى

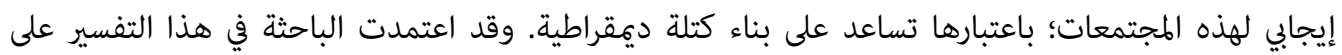
النموذج المعتمد على الأداء Performance-based Model الذي يوضح أن الثقة السياسية هي إحدى الأدوات التي

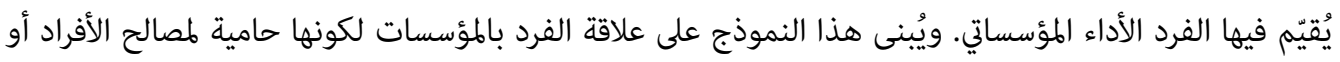
المواطني؛ ومن ثمّ، يدل تقييم المؤسسات على نحو إيجابي على أداء هذه المؤسسات الحامي لمصالح المواطنين، وهو

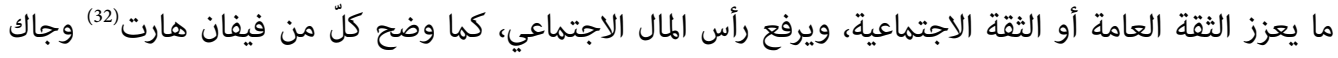

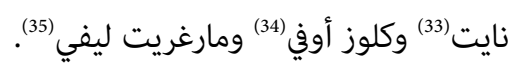

ويذكر ويليام ميشلر وريتشارد روز أن النموذج المبني على الأداء يختلف عن غيره من النماذج في تفسير العلاقة بين الثقة السياسية والثقة العامة من حيث التوقيت فقط، حيث إن هذا النموذج يعتمد على نظرة المواطنين إلى الأداء

\footnotetext{
28 Spierings, p. 2.

29 Jamal, p. 2

30 Ibid.

31 Ibid.

32 Vivien Hart, Distrust and Democracy: Political Distrust in Britain and America (Cambridge: Cambridge University Press, 1978).

33 Jack Knight, "Social Norms and the Rule of Law: Fostering Trust in a Socially Diverse Society," in: K.S. Cook (ed.), Trust in Society, Russell Sage Foundation Series on Trust, vol. 2 (New York: Russell Sage Foundation, 2001), pp. 354-373.

34 Claus Offe, "How Can we Trust our Fellow Citizens," Democracy and Trust, vol. 52 (1999), pp. $42-87$.

35 Margaret Levi, "Social and Unsocial Capital: A Review Essay of Robert Putnam's Making Democracy Work," Politics \& Society, vol. 24, no. 1 (1996), pp. 45-55.
} 
المؤسساتي في الوقت القريب والأحوال المؤقتة، والتي تعبّر عن الإجابة عن السؤال: "ماذا قدّم لي المجتمع مؤخرًا؟"(36). لهذا فإن الثقة السياسية، بحسب هذا النموذج، غير متجذرة في التاريخ، بل إنها تعبر عن التجارب الحديثة. قدّم سبيرنغز دراسة من أهم الدراسات على المستوى المراجعة النظرية، درس فيها محددات الثقة العامة في الوطن العربي، وركَّز على عدة محاور لضبط العوامل المؤثرة في الثقة العامة نفسها، ومنها الامتيازات الاجتماعية والاقتصادية، والدين والتدين، والنظام السياسي والقانوني. وقد وجد أن فكرة اختلاف الأوضاع السياسية والاجتماعية بين الدول الديمقراطية وغير الديمقراطية تؤدي إلى اختلاف طريقة تأثير العوامل في مستويات الثقة. ووجد أن دخول الأفراد لا تؤثر في مستويات الثقة العامة، على عكس النظريات التي تفسر هذه العلاقة في النظم الديمقراطية، في حين أن زيادة التعليم قللت من مستويات الثقة العامة لدى الأفراد(37.) كما وجد الباحث أن للالتزام الديني في بعض الدول أثرًا إيجابيَّا في الثقة العامة، مع التركيز على أثر حوكمة الشؤون الدينية وشدة استبداد النظام السياسي في قوة هذا الأثر (38). وتكمن أهم مخرجات دراسته في ضرورة مراجعة النظريات المستخدمة في تفسير العلاقة بين الأفراد والمجتمع، وفهم تأثير الثقة العامة وآلية عملها في سياق الدول غير الديمقراطية.

وباتباع مسار بحثي مقارب للدراسات السابقة، تستخدم هذه الدراسة بيانات لاثنتي عشرة دولة عربية (خلال الفترة 2015-2017)، من أجل دراسة الثقة العامة في الوطن العربي باستخدام بيانات المؤشر العربي. وهذه البيانات - بحسب اعتقادي - مُ تُستَخَم قطُّ لدراسة الثقة العامة على مستوى الوطن العربي. كما تتميز الدراسة بأنها تركز على الفترة اللاحقة للربيع العربي التي أثّرت تأثيرًا كبيرًا في المجتمعات العربية بطريقة مباشرة أو غير مباشرة، خاصة في مستويات عدم الاستقرار السياسي الذي تعيشه هذه المجتمعات.

أمّا الجانب الآخر من أثر رأس امال الاجتماعي، فيوضحه أليخاندرو بورتيز في دراسة تعرض أصول رأس المال وتعريفاته لبعض المؤلفين. وقد عدد الباحث بعض العوائد السلبية لرأس المال الاجتماعي؛ منها أن الترابط العالي بين أفراد المجموعة يحول دون نفاذ الآخرين إليه؛ ما يجعله حكرًا على أعضاء المجموعة أصحاب الامتيازات. ويضيف إلى ذلك أن المشاركة الجماعية مطلوبة، وأنها قد تتعدى، في كثير من الحالات، على الحرية الفردية، وأن تراكم رأس المال الاجتماعي يتحول، في بعض الحالات، إلى حالة ضبط اجتماعي تواجه الفردية وفكرة الانتقال بين المجموعات، وأن توافر هذا الترابط بين المجموعات غير الأخلاقية (مثل عصابات المافيا، وحلقات القمار) يعزز وجودها ويشكل حماية لها (39. لذلك، عند التحدث عن رأس المال الاجتماعي، يجب التركيز على الأعمال الجمعية التي لها آثار إيجابية

$$
\text { في المجتمع، والتي تعزز مدنية المجتمع وديمقراطيته. }
$$

36 William Mishler \& Richard Rose, "Trust, Distrust and Skepticism: Popular Evaluations of Civil and Political Institutions in Postcommunist Societies," The journal of politics, vol. 59, no. 2 (1997), pp. 418-451.

37 Spierings, p. 2.

$$
38 \text { 3 قاس الباحث الالتزام الديني من خلال استخدام متغير يقيس درجة التزام المُستجيب بصلاة الجمعة أو زيارة الكنيسة يوم الأحد. }
$$

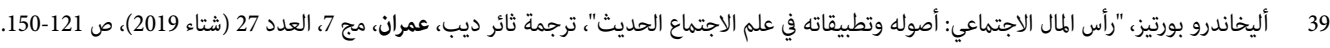




\section{ثانيًا: خلفية وصفية عن البيانات المستخدمة في الإطار العرببي}

تهدف هذه الدراسة إلى تعرف محددات رأس المال الاجتماعي في الوطن العربي باستخدام بيانات المؤشر العربي(40.

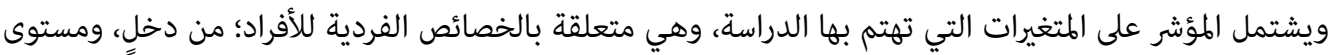
تعليمي، وخصائص أسرية، إضافة إلى قياس مدى الثقة العامة للأفراد؛ الثقة السياسية، والثقة على الثئى المستوى الشخصي، وغير ذلك من المتغيرات. وتقتصر العينة المستخدمة في الدراسة على ثلاثة استطلاعات من بيانات المؤشر؛ هي استطلاعات الأعوام 2015، و2016، و2017 و2018؛ وذلك بسبب توافر البيانات الخاصة بالثقة العامة في هذه الاستطلاعات. وشملت العينة اثنتي عشرة دولة عربية (الأردن، وتونس، والجزائر، والسعودية، والسودان، والعراق،

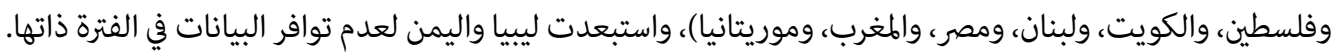
وقد بلغ عدد المشاهدات المستخدمة في التحليل ما يزيد على 38 ألف مشاهدة. ويوضح الجدول (1) وصفات ولفيا إحصائيًّا

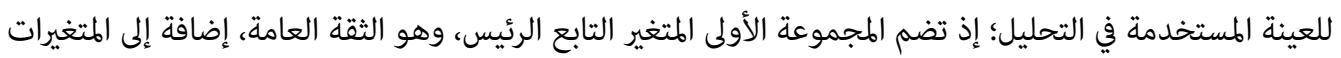

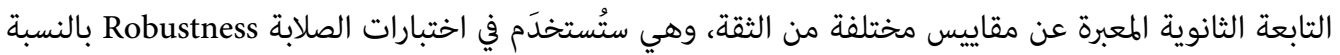

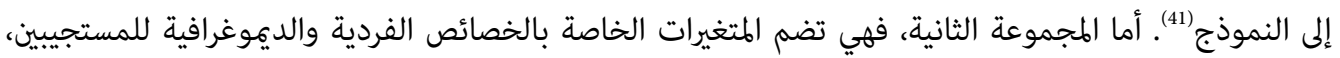

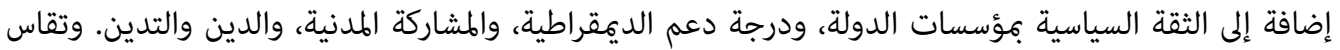

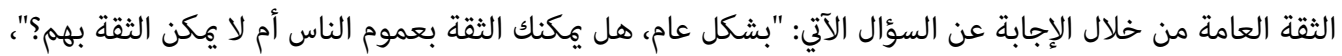

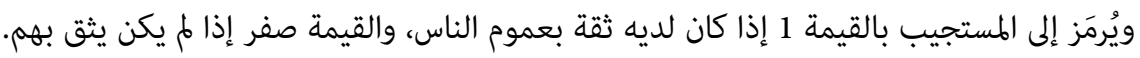

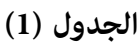

وصف إحصائي لبيانات العينة المستخدمة في التحليل

\begin{tabular}{|c|c|c|c|c|}
\hline 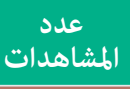 & الانحراف & المتوسط الحسابي & الوصف & المتغير \\
\hline \multicolumn{5}{|c|}{ المتغيرات التابعة (الثقة) } \\
\hline 38165 & 0.452 & 0.28 & القيمة 1 إذا كان المستجيب يثق بعموم الناس، وصفر إذا & الثقة العامة \\
\hline \multicolumn{5}{|c|}{ الثقة الخاصة } \\
\hline 18224 & 0.48 & 0.36 & مدى ثقتك بجيرانك: القيمة 1 إذا كانت الإجابة "أثق بدرجة & الجيران \\
\hline 18226 & 0.5 & 0.45 & مدى ثقتك بالأشخاص الذين تعرفهم: القيمة 1 إذا كانت & الأشخاص الذين تعرفهم \\
\hline 18042 & 0.2 & 0.04 & كانت الإجابة "أثق بـ بدرجة عالشخاص الذين تلتقيهم أول مرة: القيمة 1 إذا & الأشخاص الذين التقيت بهم \\
\hline
\end{tabular}

40

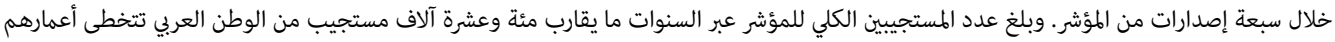

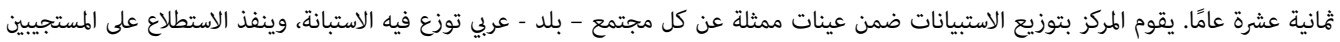

ميدانيًا من خلال مقابلات وجاهية. 41 تشير صلابة النتائج، أو متانتها، إلى أن مخرجات ماتهات التحليل وتقديراته دقيقة باستمرار، حتى في حالة تغيير متغيّر واحد أو أكثر من المتغيرات أو الفرضيات المستخدمة في توقع النموذج. 


\begin{tabular}{|c|c|c|c|c|}
\hline المشاهدات & الانحراف المياري & الحسايط المساي & الوصف & المتتغير \\
\hline \multicolumn{5}{|c|}{ المتغيرات المستقلة } \\
\hline & & & الهقياس من 1-4 "الرقم 4 يعبر عن الثقة المطلقة". & الثقة بالمؤسسات الحكومية \\
\hline 36630 & 1.02 & 2.97 & 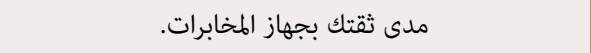 & الثقة بالمخابرات \\
\hline 38165 & 0.82 & 3.44 & مدى ثقتك بالجيش الوطني. & 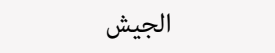 \\
\hline 32582 & 0.96 & 1.95 & مدى ثقتك بالأحزاب السياسية. & 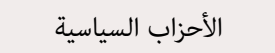 \\
\hline 38165 & 1.06 & 2.51 & مدى ثقتك بالحكومة الحالية. & الحكومة \\
\hline 34907 & 1.04 & 2.22 & مدى ثقتك بمجلس النواب. & 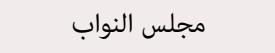 \\
\hline 34296 & 0.96 & 2.93 & مدى ثقتك بجهاز الشرطة. & 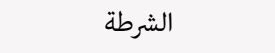 \\
\hline 25529 & 1.02 & 2.97 & مدى ثقتك بالجهاز القضائي. & 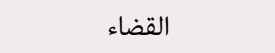 \\
\hline 38165 & 0.453 & 0.29 & 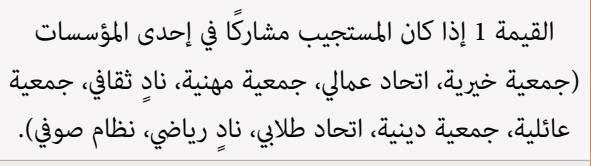 & 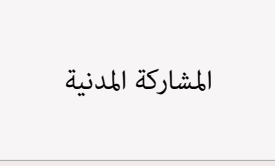 \\
\hline 38165 & 0.49 & 0.48 & أجل القيمة 1 إذا كان المستجيب غير موافق بشدة على أنه من الأمن، فإنه من المبرر التعدي على حقوق الإنسان في بلده. & حقوق الإنسان \\
\hline 38165 & 0.4 & 0.21 & القيمة 1 إذا كان تحصيل المستجيب العلمي أكثر من & 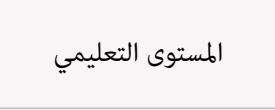 \\
\hline 38165 & 0.46 & 0.3 & 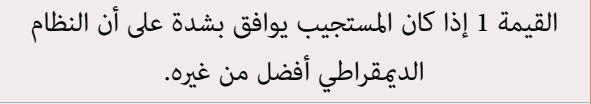 & 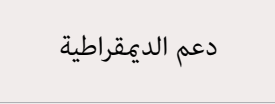 \\
\hline 38165 & 14426.56 & 2925.3 & دخل الأسرة محولًا إلى القوة الشرائية بالدولار باستخدام & 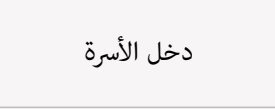 \\
\hline 38165 & 0.5 & 0.49 & القيمة 1 إذا كان المستجيب ضمن الفئة العمرية (18-34). & 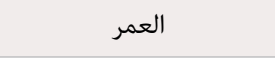 \\
\hline 38165 & 0.22 & 0.95 & القيمة 1 إذا كان المستجيب مسلمًا، وصفر في غير ذلك. & 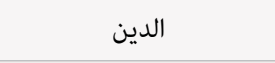 \\
\hline 38165 & 0.41 & 0.21 & القيمة 1 إذا وصف المستجيب نفسه بأنه متدين جدًا، & 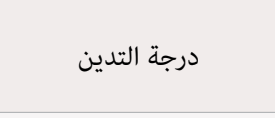 \\
\hline 38165 & 0.5 & 0.47 & القيمة 1 إذا كان المستجيب أنثى، وصفر إنْ م يكن كذلك. & 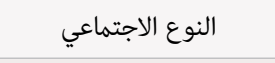 \\
\hline 38165 & 0.5 & 0.5 & القيمة 1 إذا كان المستجيب يعتقد أن الفساد منتشر بشكل في بلده، وصفر في غير ذلك. & 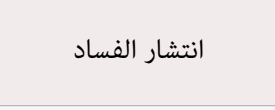 \\
\hline 38165 & 0.2 & 0.04 & 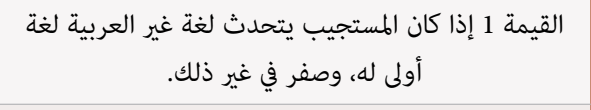 & 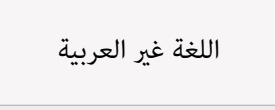 \\
\hline 38165 & 2.39 & 5.19 & 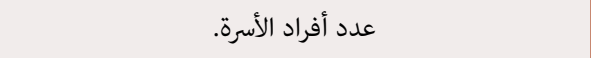 & 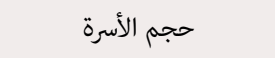 \\
\hline
\end{tabular}


يوضح الجدول الوصفي أن مستويات الثقة العامة في العينة تساوي 28 في المئة، وهي نسبة متدنية مقارنةً بالدول المتقدمة في الفترة نفسها (السويد 63.8 في المئة، والنرويج 72.8 في المئة، ونيوزيلندا 59.5 في المئة)(42). وبالرغم من من منان ذلك، فإن هذه النسبة تختلف بحسب الدول والأعوام كما يوضح الشكل (نسبة الثقة العامة)؛ إذ نجد دولًا، مثل

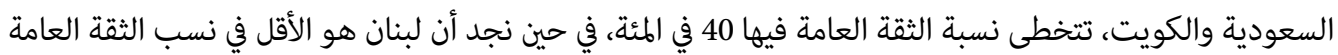

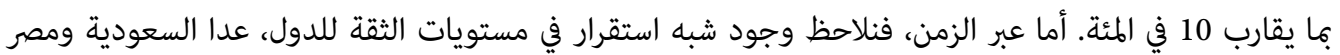
وموريتانيا، التي ازدادت فيها مستويات الثقة العامة في عام 2018 على نحو ملحوظ.

\section{شكل يبين نسبة الثقة العامة في عدد من الدول العربية (2015-2018)}

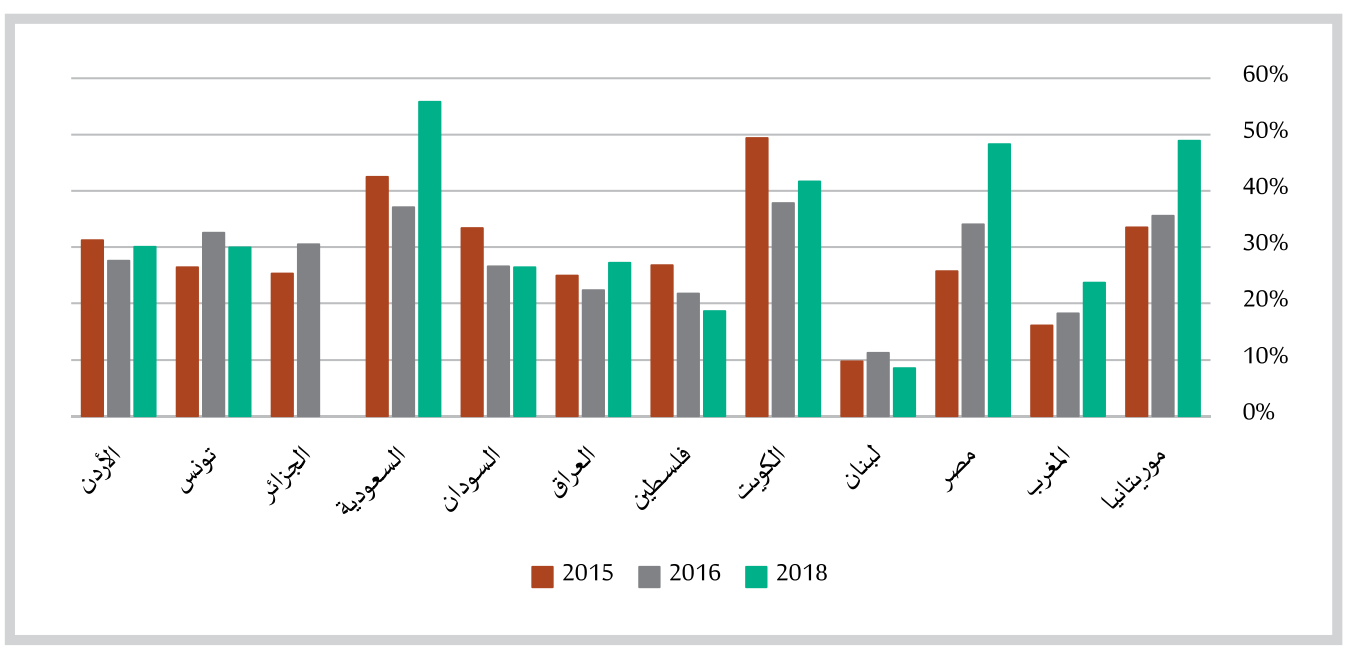

المصدر: المركز العربي للأبحاث ودراسة السياسات، المؤشر العربي، استنادًا إلى الفترة 2015-2018.

وفيما يتعلق بمقاييس الثقة الأخرى، نجد أن المجموعات الأقرب إلى المستجيب ذات مستويات ثقة أعلى من غيرها؛

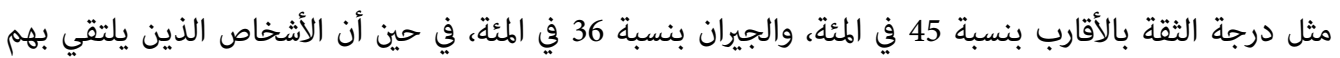
المستجيب أول مرة لا يتعدى مستوى الثقة بهم نسبة 5 في المئة.

أما فيما يتعلق بالمتغيرات التي تعبر عن تقييم المستجيبين لأداء المؤسسات السياسية، فأهمها الثقة السياسية التي تعبر عن الثقة بالمؤسسات السياسية الموجودة في الدولة؛ مثل القضاء، والشرطة، والجيش، والبرمان، والأحزاب السياسية، والحكومة، وغيرها. وتقاس الثقة لهذه المؤسسات بمقياس يأخذ القيمة (1) إذا كان المستجيب لا يثق على على

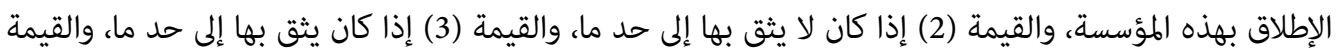

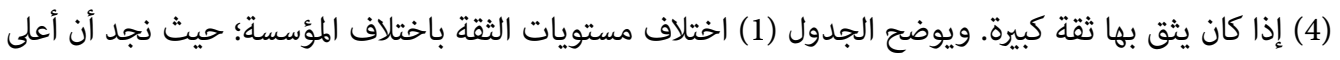
مستويات الثقة موجودة في الجيش، في حين توجد أقلها في الأحزاب السياسية. وقد استخدمت التحليل العاملي 
Factor Analysis عن الثقة السياسية لكل دولة من الدول العربية. وقمت بالتحليل العاملي لهذه الأسئلة لكل دولة على حدة؛ وذلك بسبب اختلاف المؤسسات السياسية الموجودة في كل دولة من الدول العربية، فجاءت نسبة الموثوقية المقيسة بألفا كرونباخ لمختلف الدول بنسبة تتخطى 70 في المئة، وهي نسب جيدة جدًّا، على نحو ما توضّحهه نتائج التحليل في

(2) الجدول (2) (2) (2)

الجدول (2)

نتائج متانة التحليل العاملي للثقة السياسية

\begin{tabular}{|c|c|c|}
\hline ألفا كرونباخ & عدد المؤسسات & الدولة \\
\hline$\% 74$ & 7 & الأردن \\
\hline$\% 74$ & 6 & تونس \\
\hline$\% 83$ & 7 & الجزائر \\
\hline$\% 81$ & 6 & السعودية \\
\hline$\% 85$ & 7 & السودان \\
\hline$\% 77$ & 6 & العراق \\
\hline$\% 85$ & 5 & فلسطين \\
\hline$\% 70$ & 5 & الكويت \\
\hline$\% 71$ & 6 & لبنان \\
\hline$\% 79$ & 6 & مصر \\
\hline$\% 84$ & 6 & المغرب \\
\hline$\% 90$ & 7 & موريتانيا \\
\hline
\end{tabular}

المصدر: من إعداد الباحث، استنادًا إلى التحليل الإحصائي للبيانات.

استُخدمت طريقة المكونات الرئيسة Principal Components لاستخراج عامل الثقة السياسية، وأظهرت نتائج هذا التحليل وجود عامل واحد يعبر عن الثقة السياسية لكل دولة عربية على اختلاف مؤسساتها السياسية. وقد جمعت عامل الثقة السياسية لكل دولة عربية في متغير واحد سمّيته "الثقة السياسية". أما المتغيرات الأخرى لقياس تقييم الأداء المؤسساتي في الدول، فهي: أولًا، دفاع المستجيب عن حقوة الفوق الإنسان؛ إذ إن هذا المتغير وهمي Dummy variable التعدي على حقوق الإنسان، ويأخذ صفرًا في غير ذلك(43)، ويتوقع أن يقيّم المستجيب المدافع عن حقوق الإنسان

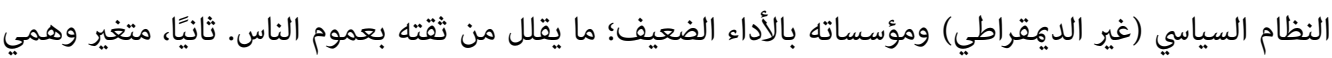

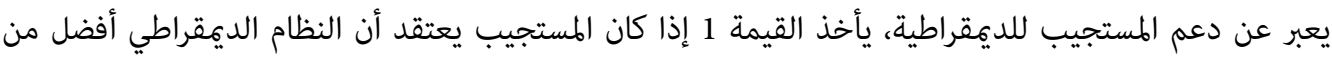


غيره من الأنظمة. ثالثًا، متغير وهمي يأخذ القيمة 1 إذا كان المستجيب يعتقد أن الفساد منتشر بشكل كبير في البلد، ويأخذ صفرًا في غير ذلك.

ويمكن تلخيص هذه المتغيرات بأنها تعبر عن مدى تقييم المستجيبين لأداء المؤسسات السياسية في البلد، ونتوقع أنه

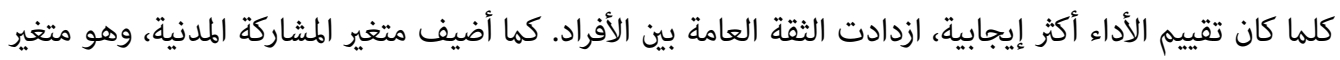

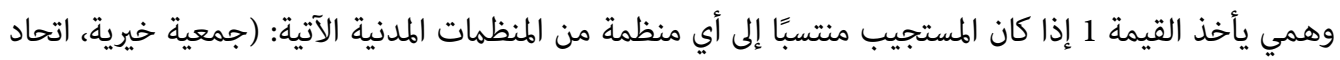
عمالي، جمعية مهنية، نادٍ ثقافي، جمعية عائلية، جمعية دينية، اتحاد طلابي، نادٍ رياضي، طريقة صوفية إنية). وأخيرًا

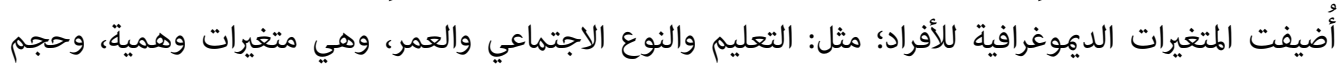

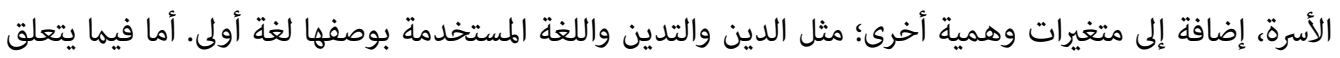
بدخل الأسرة، فقد حولت العملة المحلية إلى قيمتها بالقوة الشرائية باستخدام معاملات القوة الشرائية لكل دولة بحسب بيانات البنك الدولي (44).

\section{ثالثًا: المنهجية وأدوات التحليل}

تستخدم هذه الدراسة نموذج Logit في تحليل تأثير المحددات المتوافرة في الثقة العامة باستخدام البيانات المجمّعة Pooled Data صفر إذا كان لا يثق بهم. ويجدر التنبيه إلى أن نيوتن (45) وغلاسير [وآخرون] (46) انتقدوا استخدام هذه إنغيت الطريقة لوصف الشخص بأنه واثق بغيره أو غير واثق، كما انتقدوا بنية السؤال ذاته، فـ "الثقة بعموم الناس" تعتمد على إنى تعريف الشخص نفسه لن هم عموم الناس بالنسبة إليه. ومع ذلك فإن هذا المقياس للثقة العامة استخدمه العديد من الباحثين لتحديد محددات الثقة، وسأتبع في هذه الدراسة منهجية بيورنسكوف (47) وألسينا ولافرارا (48) وأريك

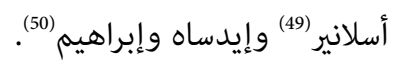

أما المتغيرات المستقلة، فهي تتمثل في ثلاث مجموعات هي: المتغيرات المعبرة عن الأداء الحكومي، والدين والتدين،

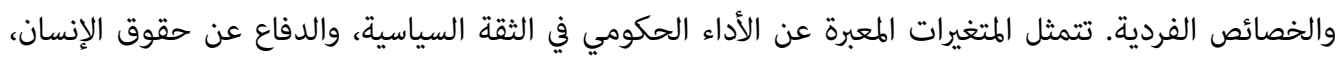

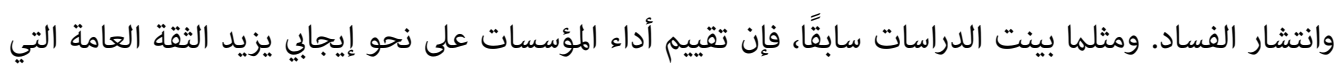

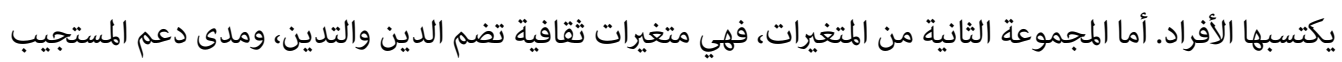

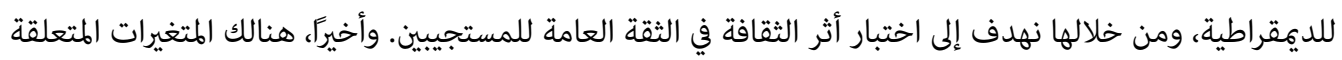
بالخصائص الفردية؛ مثل النوع الاجتماعي لاختبار الفروقات في الثقة بين الذكور والإناث، والعمر لاختبار الفروقات

44 World Bank Group, "PPP Conversion Factor, GDP (LCU per International \$)," accessed on 11/11/2019, at: https://cutt.us/qzNvb

45 Newton, p. 3.

46 Glaeser et al., p. 3.

47 Bjørnskov, p. 4.

48 Alesina \& La Ferrara, p. 4.

49 Eric M. Uslaner, "The Foundations of Trust: Macro and Micro," Cambridge Journal of Economics, vol. 32 (2008), pp. 289-294.

50 Sulemana \& Issifu, p. 5. 
بين فئة الشباب (-18 34) وفئة الأكبر سنًّا، والتعليم لضبط الاختلاف بين المتعلمين (الحاصلين على شهادات جامعية) وما دونهم بالتحصيل العلمي، إضافة إلى متغير الدخل وعدد أفراد الأسرة. كما أضفنا متغيرًا وهميًا للغة بالنسبة إلى المتحدثين بغير اللغة العربية كلغة أولى، ويمكن أن نعدّ المتحدثين بغير اللغة العربية، والإناث، وغير المسلمين، مجموعات يُحتمل أن تتعرض للتهميش أو التميز الاجتماعي في الإطار العربي؛ لذلك أُضيفت إلى التحليل. وأخيرًا تحكّمتُ في عامل الزمن لضبط التغيرات الحاصلة عبر السنوات، وعامل المكان من خلال إضافة متغيرات وهمية على مستوى المحافظات الإدارية لكل بلد عربي، وذلك لضبط خصائص المحافظات العربية الثابتة التي لا تتغير عبر الزمن؛ مثل الثقافة، واللامساواة، وغيرهما. ولهذا فإن التحليل بين المستجيبين مبني على المقارنة بينهم داخل المحافظة نفسها؛ ما يضيف إلى النموذج قوة تفسيرية أكبر وأكثر دقة. وقد استُخدم التحليل على مستوى المحافظة، وليس على بلى

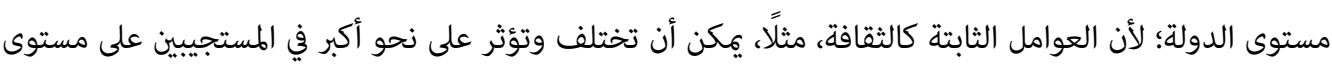
المحافظة أكثر من تأثيرها على مستوى الدول. ومن ثمّ، أتوقع أن إضافة المحافظات تضبط تلك العناف العوامل بطريقة أفضل وأدق؛ لهذا يمكن كتابة النموذج المُستخدَم في هذه الدراسة بحسب المَّلي المعادلة الآتية:

$$
\text { Trust }_{i d t}=\mathrm{a}+\mathrm{b}_{1} P C_{i}+\mathrm{b}_{2} C u l_{i}+\mathrm{b}_{3} I C_{i}+\mathrm{d}+\mathrm{t}+\mathrm{e}_{i d t}
$$

إنّ صيغ المتغير التابع، وهو الثقة العامة Trust كمتغير ثنائي، يأخذ القيمة 1 إذا كان المستجيب يثق بعموم الناس،

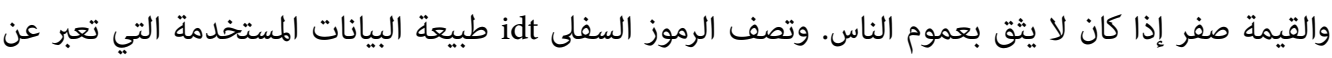

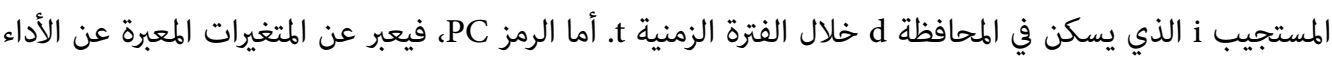
الحكومي (الثقة السياسية، والفساد، ودعم حقوق الإنسان) للمستجيب i. وأما مجموعة المتغيرات Cul، فتعبر عن ثقافة المستجيب المتعلقة بالدين والتدين ودعم الديمقراطية للفرد i. وتعبّر المجموعة IC عن الخصائص الفردية والديموغرافية للمستجيب أ؛ مثل التعليم، والعمر، وعدد أفراد الأسرة، وغيرها. في حين يعبر الرمز $\delta$ عن مجموعة من المتغيرات الوهمية التي تضبط تأثير المحافظات وهي التأثيرات التي تختلف من محافظة إلى أخرى، ولكنها

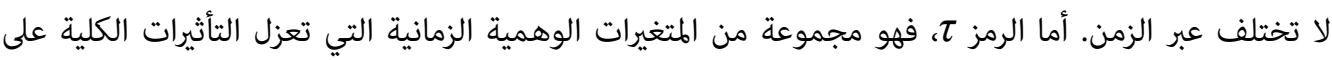

$$
\text { مستوى المحافظات، والتي تغيرت عبر الزمن. }
$$

والجدير بالذكر أن من أهم التحديات التي تواجه هذا النموذج هي مشكلة التعريف بحسب بيورنسكوف (51)، والتي يشار إليها بمصطلح Identification Problem، فقد أوضح أنه يجب الأخذ بالحسبان أن وجود متغيرات لا تتغير عبر الزمن، أو ذات خصائص ممتدة في الزمن، قد يمثل مشكلة تداخل Endogeneity مع متغير الثقة، خاصة أن إن الثقة العامة هي من المتغيرات المعتمدة على المسار التتبعي التاريخي Path Dependant. وأهم هذه المتغيرات، بحسب الباحث، هي اللامساواة التي لا تتغير، أيضًا، على نحو كبير عبر الزمن. ومن ثم، فإن إضافة متغيرات وهمية

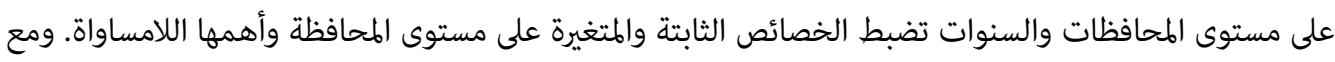
ذلك، لا يمكن تأكيد وجود علاقة خطية بين المتغيرات التي أضيفت على الثقة العامة. 


\section{رابعًا: التحليل وتقديمم النتائج}

تعرض الدراسة في هذا القسم نتائج تطبيق المنهجية المستخدمة لمعرفة محددات الثقة الاجتماعية في الوطن العربي، ابتداءً بعرض نتائج التحليل الرئيسة "الجدول (3)" مع شرح هذه النتائج ومناقشتها؛ ومن ثم النائه الانتقال إلى اختبارات

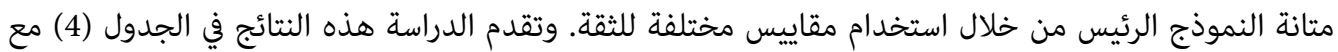
عرض ما توصلت إليه هذه الاختبارات وشرحه. ويظهر الجدول (3) نتائج التحليل لمحددات الثقة العامة في الوطن

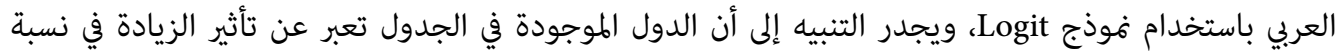

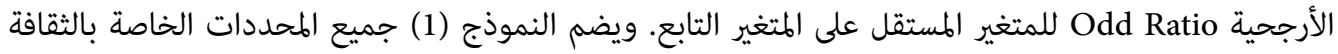
والخصائص الفردية، من دون إضافة متغيرات التحكم الخاصة بالوقت والمنطقة السكنية والثقة السياسية. وكما

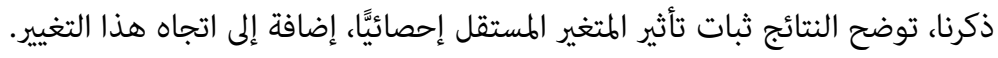

(3) الجدول

\section{نتائج تحليل نهوذج اللوجستي Logit Model لهحددات الثقة العامة}

\begin{tabular}{|c|c|c|c|}
\hline \multicolumn{3}{|c|}{ المتغير التابع: الثقة العامة } & المتغيرات المستقلة \\
\hline (3) & (2) & (1) & \\
\hline${ }^{* * *} 0.421$ & & & الثقة السياسية (متغير عاملي Factor) \\
\hline 0.00751 & & & المشاركة المدنية \\
\hline${ }^{* *} 0.0879$ & & & الدفاع عن حقوق الإنسان \\
\hline 0.0173 & -0.00154 & 0.0394 & الدرجة العلمية: أعلى من الثانوية \\
\hline 0.0478 & 0.0635 & $* * * 0.113$ & دعم الديمقراطية \\
\hline$* * * 0.0734$ & ${ }^{* *} 0.0684$ & 0.0344 & دخل الأسرة (محسوبًا بالقوة الشرائية، بصيغة اللوغاريتم) \\
\hline$* * *-0.101$ & $* * *-0.118$ & $* * *-0.106$ & العمر (الفئة بين 18-34 عامًا) \\
\hline 0.00636 & -0.0607 & $* * * 0.487$ & 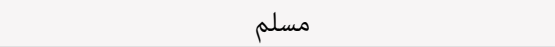 \\
\hline 0.154 & 0.153 & -0.0145 & التدين (درجة عالية) \\
\hline 0.0896 & 0.132 & ${ }^{* *} 0.369$ & متغير متداخل (مسلم بدرجة تديّن عالية) \\
\hline$* * *-0.242$ & $* * *-0.439$ & $* * *-0.524$ & الفساد (بدرجة عالية) \\
\hline-0.0416 & -0.0117 & -0.0129 & 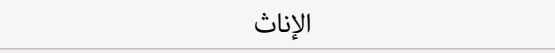 \\
\hline$* * *-0.320$ & $* * *-0.373$ & $* * *-0.776$ & اللغة الأولى (غير العربية) \\
\hline \multirow[t]{2}{*}{0.00285} & 0.00194 & 0.00122 & 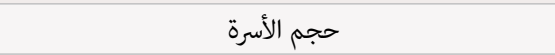 \\
\hline & & $* * *-0.192$ & مكان السكن (الحضر) \\
\hline$* * *-1.502$ & $* * *-1.194$ & $* * *-1.313$ & المعامل الثابت Constant \\
\hline 38165 & 42229 & 40656 & عدد المشاهدات المستخدمة في التحليل \\
\hline 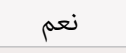 & 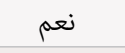 & لا & متغير وهمي (الدول) \\
\hline 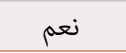 & 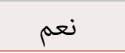 & لا & متغير وهمي (السنة) \\
\hline
\end{tabular}

تشير الرموز (*) إلى الدلالة الإحصائية للقيم التقديرية للمتغير، حيث (** p<0.1*0. جميع معاملات الخطأ ضبطت Clustered على مستوى المحافظة. المصدر: المرجع نفسه. 
وبناء على ذلك، فإن محددات الثقة العامة ذات الدلالة الإحصائية في النموذج (1) هي دعم الديقراطية، والعمر،

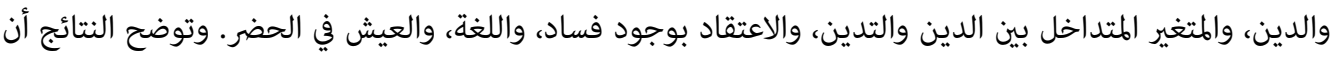
المستجيبين الذين يعتقدون أن النظام الديمقراطي أفضل من غيره من الأنظمة تزداد احتمالية ثقتهم بعموم الناس، مقارنةً بالذين لا يعتقدون بأفضلية النظام الديمقراطي.

يضم متغير العمر فئة الشباب؛ ما يعني أن هذه الفئة (18-34) تقل احتمالية ثقتها بعموم الناس عن فئة الأعمار

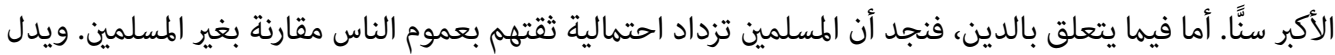

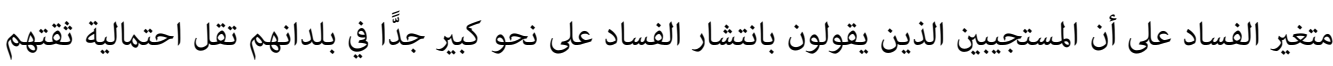

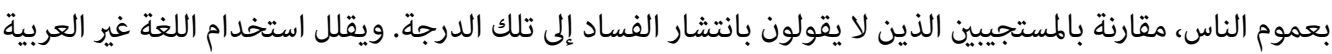

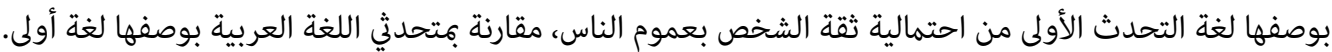
وأخيرً، نجد أن سكان المناطق الحضرية تقل احتمالية ثقتهم بالناس، مقارنة بسكان المناطق الريفية. ويعاني هذا النموذج تحيزًا من جرّاء عدم التحكم في بعض المتغيرات وخاصة التي ذكرتها الأدبيات، والتي لا تتغير

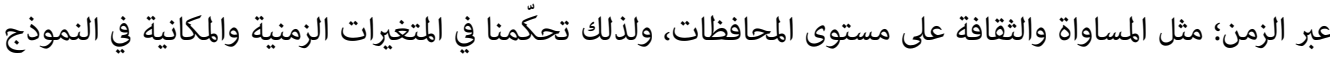

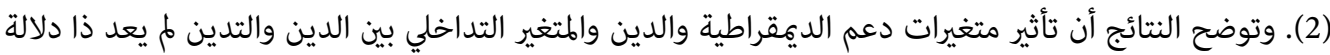

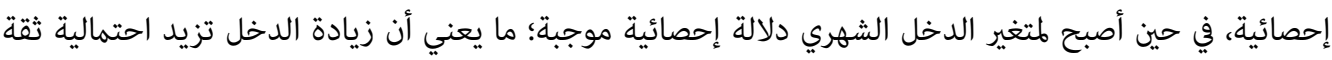
المستجيب بعموم الناس. وقد بقي لمتغيرات (العمر، والفساد، واللغة) دلالة إحصائية في اتجاه عكسي يقلل من من احتمالية ثقة المستجيب بعموم الناس.

وفي النموذج الأخير (3) أُضيفَت المتغيرات الخاصة بتقييم الأداء الحكومي؛ مثل الثقة السياسية والدفاع عن حقوق

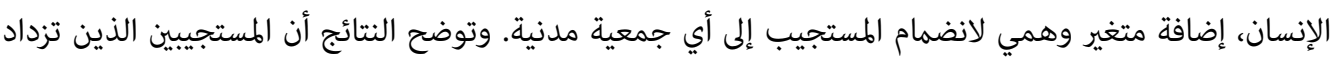

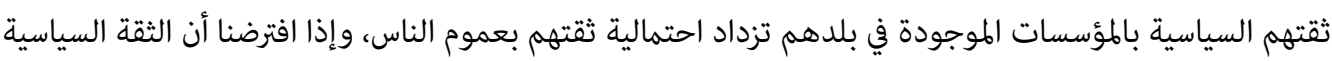

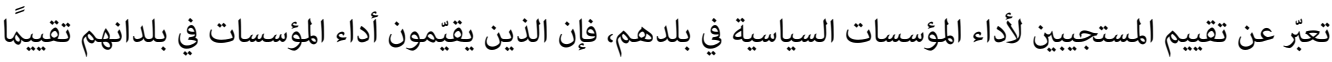
إيجابيًا، تكون احتمالية أن يرى هؤلاء أن هذه المؤسسات تحمي مصالحهم أعلى؛ ومن ثم تزداد ثقتهم العامة. أما فيما يتعلق بالانخراط المدني، فإن احتمالية الثقة بعموم الناس بالنسبة إلى المستجيبين المنضمين إلى جمعيات مدنية إنهات

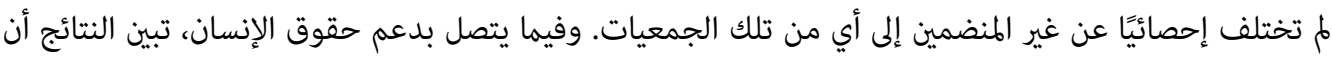

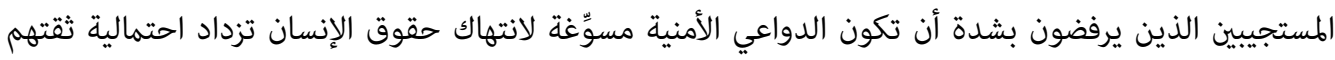

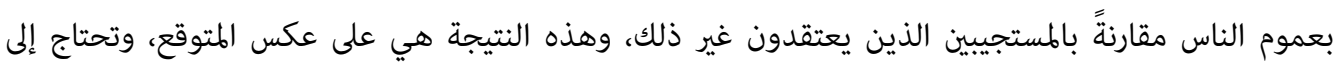

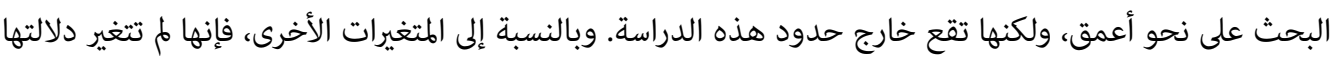
الإحصائية أو اتجاه تأثيرها في الثقة العامة.

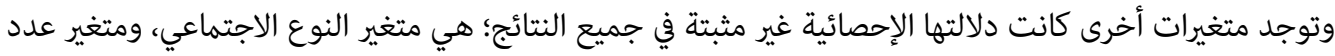

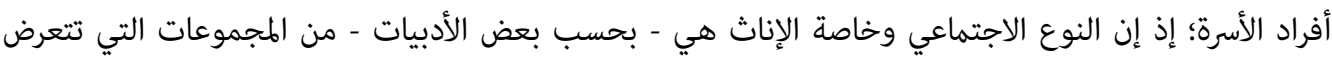

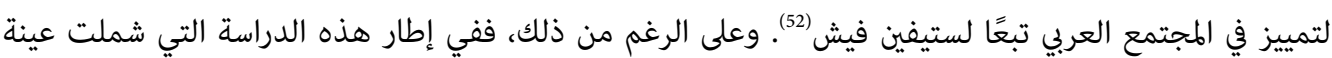


تمثل أكثر من 80 في المئة من الوطن العربي، تبين أنّ احتمالية ثقة الإناث بعموم الناس لا تختلف عن ثقة الذكور

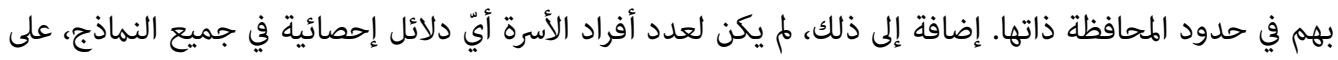

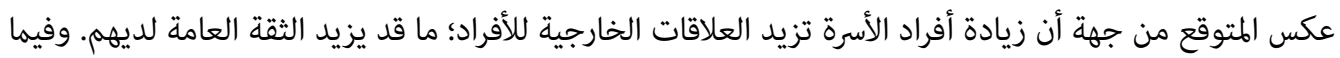

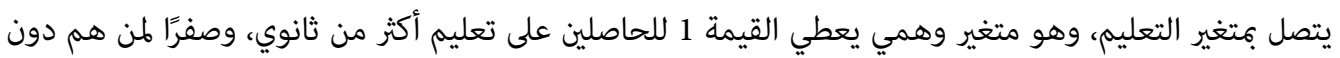
ذلك، بيّنت النتائج أن هذه الفئة لا تختلف احتمالية ثقتها بعموم الناس عن أصحاب التعليم التعليم الثانوي أو الأقل منه.

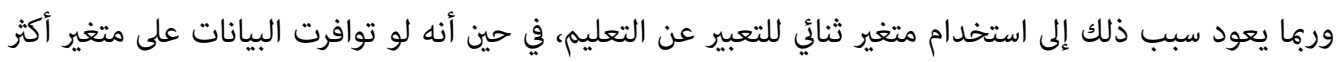
ديناميكية، مثل سنوات التعليم، لوجدنا نتيجة مختلفة.

وأظهر التحليل نتائج مثيرة للاهتمام، خاصة لدى مقارنتها بدراسة سبيرنغز (53) والنتائج التي توصل إليها(54) إذ وجد

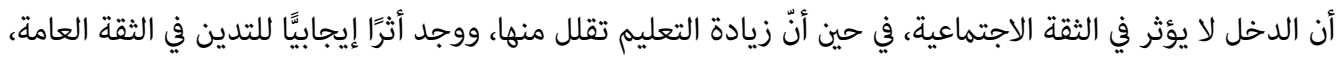

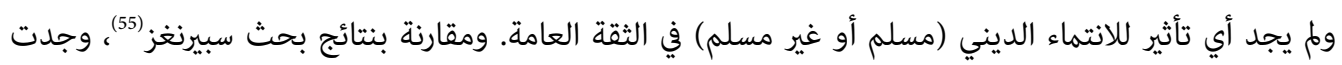

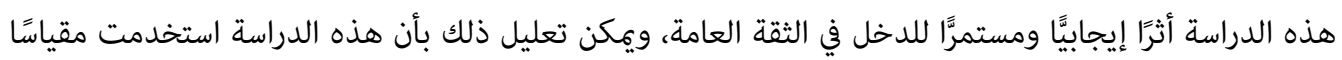

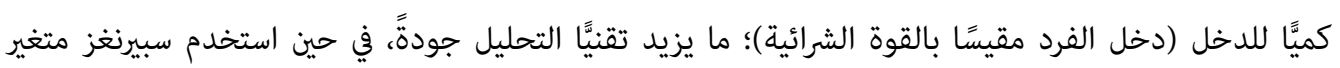
حالة العمل (يعمل، أو عاطل عن العمل) للدلالة على الوضع الاقتصادي للفرد. وتتماشى هذه النتيجة مع النظرية

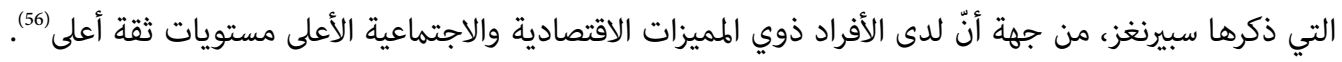
والنظرية ذاتها تنطبق على التعليم. ومع ذلك، مل تجد هذه الدراسة علاقة بين التعليم والثقة (57)، ومل تجد أيضًا أثرًا لدرجة التدين أو الدين في الثقة العامة، في حين وجدت علئ علاقة مباشرة وثابتة بين تقييم المؤسسات السياسية (متمثلة في الثقة السياسية "إيجابية"، أو انتشار الفساد في مؤسسات الدولة "سلبية") والثقة العامة، إضافة إلى وجود علاقينة سلبية بين تحدث المستجيب للغة غير العربية بوصفها لغة أولى وثقته بعموم الناس.

\section{اختبارات المتانة}

هنالك العديد من المقاييس والأسئلة الموجودة في المؤشر العربي التي يكن استخدامها للتعبير عن متغير واحد. وفيما يخص المتغيرات المستخدمة في التحليل الرئيس، فهي تتبع ما استخدمته الأدبيات من حيث نص المتغير "السؤال

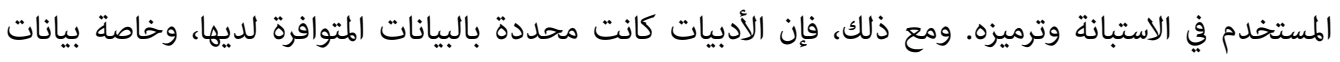

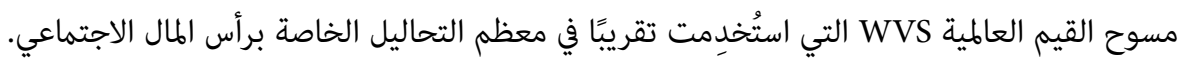
يقوم الباحث في هذا القسم باستغلال وجود متغيرات أو مقاييس أخرى للمتغيرات نفسها للتأكد من متانة النتائج وعدم تغيرها، إضافة إلى استغلال وجود بيانات عن الثقة الشخصية ببيانات المؤشر العربي الموجودة حصرًا في استبانة

53 Spierings, p. 2.

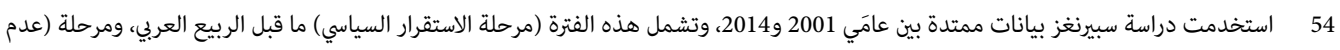

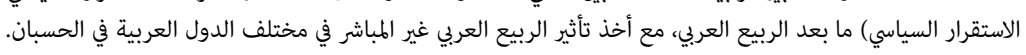

55 Ibid.

56 Ibid.

57 كما وضحت سابقًا، قد يكون السبب عدم توافر معلومات تفصيلية عن التعليم، الأمر الذي يقلل من التشتت الذي يسمح به متغير التعليم المستخدم. 
عام 2015، للمقارنة بين محددات الثقة العامة والهحددات التي قد تؤثر في الثقة المستجيبية. فالثقة بالجيران والأقارب والمستجيبين الذين تلتقي بهم أول مرة نطلق عليها الثقة الشخصية؛ لأنها تعتمد على العلاقة الشخصية بين شخص ومجموعة محددة من الأشخاص.

يُظهر النموذج 4 في الجدول (4) نتائج تحليل النموذج الأساسي الذي يقيس أثر المحددات المختلفة في الثقة العامة، مع استخدام مقاييس مختلفة للمتغيرات نفسها. وقد استبدلت في هذا النموذج الثقة السياسية بوصفها مقياسًا لأداء المؤسسات السياسية، من وجهة نظر المستجيبين، مبتغير يعبر عن متوسط الإجابات لعدة أسئلة يقيّم فيها المستجيب الأوضاع العامة في بلده، ويسمَّى

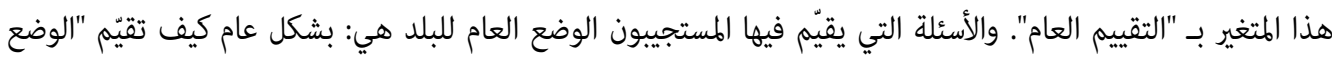

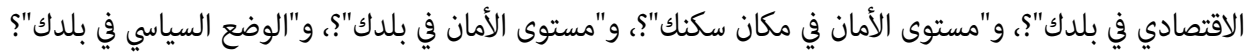
تُرمّز إجابات هذه الأسئلة من 1 إلى 4؛ إذ تعبر القيمة 4 عن تقييم جيد جدًّا. ومن خلال هذه الأسئلة، يُحسب متغير التقييم

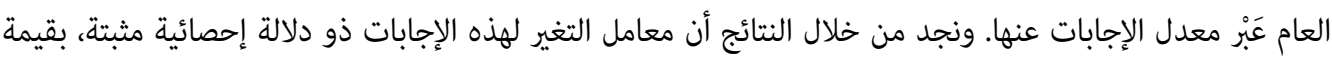
إيجابية؛ بهعنى أن ارتفاع تقييم المستجيب للوضع العام في البلد، الذي هو مرتبط بالأداء الاقتصادي والسياسي والأمني، يزيد احتمالية ثقة هذا المستجيب بعموم الناس. وتأتي هذه النتيجة مشابهة لنتيجة التحليل الرئيس الذي سبي سبق أنئ أن عرضناه أما فيما يخص التعليم، فقد استبدل الباحث المتغير الوهمي الأول، الذي يعبر عن مجموعة المستجيبين الحاصلين على تعليم

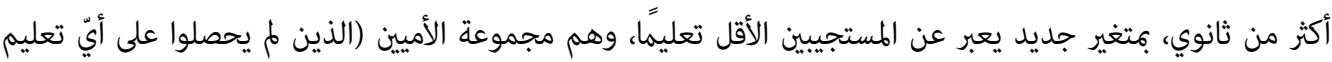

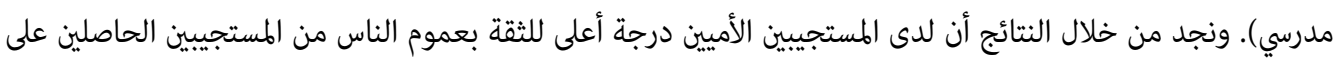
أي نوع من أنواع التعليم. وقد يُفَّر هذا الأمر بضعف قدرة وصول هؤلاء إلى المعلومات التي توضح الوضع الحقيقي في

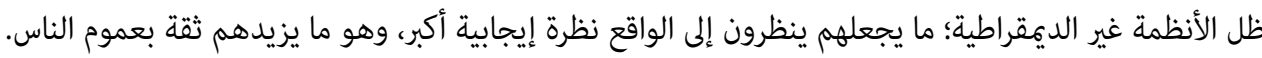
واستبدل الباحث في هذا النموذج متغير التدين بمتغير وهمي يأخذ القيمة 1 إذا كان المستجيب يؤيد أن يتولى رنه منصب رئيس الجمهورية شخص من حركة إسلامية سياسية، والقيمة صفر بالنسبة إلى المستجيبين الذين يعارضون

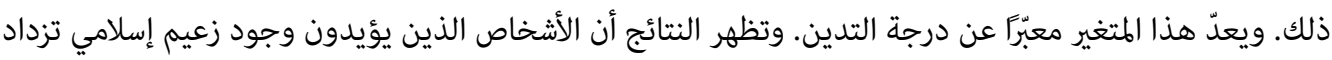
احتمالية ثقتهم بعموم الناس مقارنة بالذين يعارضون ذلك عند مستوى ثقة 5 في المئة. وهذه النتيجة مختلفة عن متغير التدين في النموذج السابق الذي لم يكن له أيّ دلالة إحصائية.

فضلًا عن ذلك، تمت إضافة متغير العمر بترميز مختلف عن الترميز السابق الذي كان يرمز إلى الفئة (18-34)؛ إذ

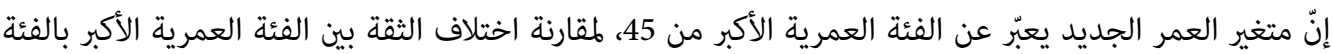

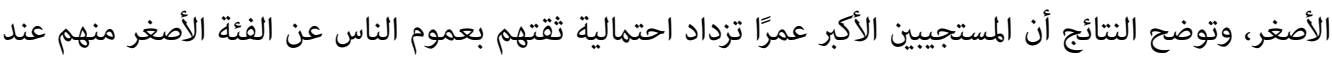

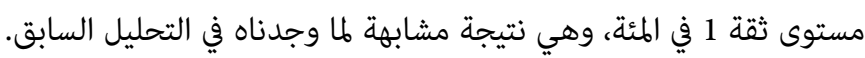

وأخيرًا، أُضيف متغير بديل لدخل الأسرة، وهو متغير وهمي يعبر عن تقييم المستجيب لوضع أسرته ماليَّا، بحيث يأخذ

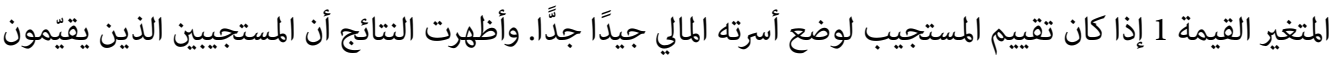

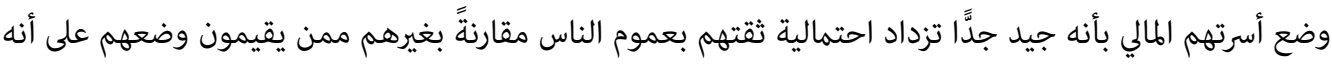

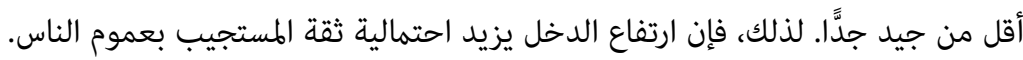




\section{الجدول (4)}

نتائج تحليل اختبارات المتانة

\begin{tabular}{|c|c|c|c|c|}
\hline قابلتهم أوّل مرة الذين & الذين تعرفهيم الأشخاص & 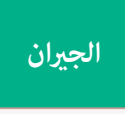 & 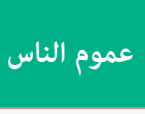 & المتغيرات التابعة: الثقة بـ \\
\hline (7) & (6) & (5) & (4) & \\
\hline${ }^{* *} 0.528$ & ${ }^{* *} 0.473$ & ${ }^{* * *} 0.458$ & & الثقة السياسية (متغير عاملي Factor) \\
\hline-0.100 & 0.0520 & 0.0297 & 0.0561 & ا مشاركة المدنية \\
\hline-0.0537 & ${ }^{* * *} 0.255$ & ${ }^{*} 0.108$ & & الدفاع عن حقوق الإنسان \\
\hline 0.0287 & -0.0225 & -0.0598 & & الدرجة العلمية: أعلى من الثانوية \\
\hline-0.118 & ${ }^{* *} 0.166$ & -0.0767 & 0.0358 & 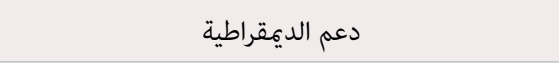 \\
\hline-0.161 & 0.0491 & 0.0151 & & دخل الأسرة (محسوبًا بالقوة الشرائية، بصيغة اللوغاريتم) \\
\hline-0.0104 & -0.00915 & $* * *-0.183$ & & العمر (الفئة بين 18-34 عامًا) \\
\hline 0.402 & * -0.314 & -0.0271 & -0.0289 & 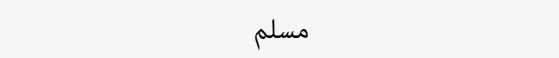 \\
\hline-0.152 & ${ }^{*}-0.310$ & -0.204 & & التدين (درجة عالية) \\
\hline 0.131 & ${ }^{* * *} 0.627$ & ${ }^{*} 0.453$ & & متغير متداخل (سلم بدرجة تدين عالية) \\
\hline$* *-0.259$ & ${ }^{\star *} 0.117$ & $\star_{0}^{*} .104$ & $* * *-0.294$ & الفساد (بدرجة عالية) \\
\hline 0.117 & ${ }^{*} 0.125$ & -0.0589 & -0.0227 & 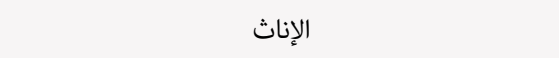 \\
\hline-0.239 & -0.137 & 0.0843 & $* * *-0.382$ & 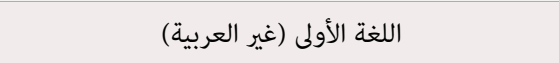 \\
\hline \multirow[t]{6}{*}{-0.0203} & 0.0128 & 0.0121 & 0.00529 & حجم الأسرة \\
\hline & & & ${ }^{* *} 0.540$ & تقييم الوضع العام \\
\hline & & & ${ }^{* *} 0.131$ & الدرجة العلمية (أميّ) \\
\hline & & & ${ }^{\star *} 0.0770$ & 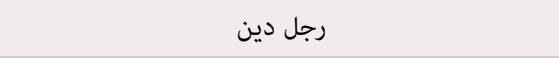 \\
\hline & & & ${ }^{* * *} 0.159$ & تقييم وضع الأسرة المالي (جيد جدًا) \\
\hline & & & ${ }^{* *} 0.091$ & الفئة العمرية (أكبر من 45 عامًا) \\
\hline$* * *-2.411$ & $* * *-1.18$ & $* *-1.066$ & $* * *-3.134$ & المعامل الثابت Constant \\
\hline 12500 & 14208 & 14196 & 39924 & عدد المشاهدات \\
\hline نعم & 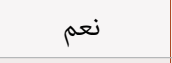 & 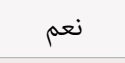 & نعم & متغير وهمي (الدول) \\
\hline لا & لا & لا & نعم & متغير وهمي (السنوات) \\
\hline
\end{tabular}

تشير الرموز (*) إلى الدلالة الإحصائية للقيم التقديرية للمتغير، حيث (** p<0.1 p جميع معاملات الخطأ ضبطت على مستوى المحافظة. 
وينتقل الباحث إلى النماذج التي تستخدم مقاييس أخرى للثقة، وهي النماذج الموضحة في الجدول (4) ذات الأرقام

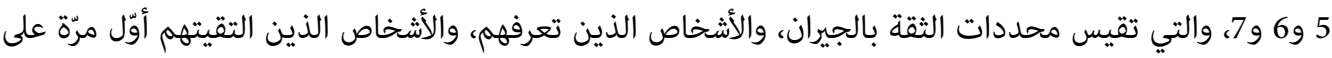

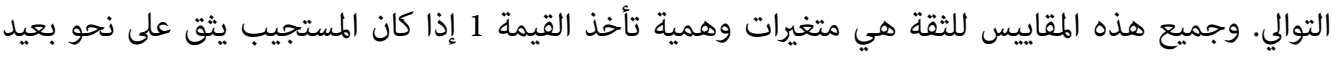

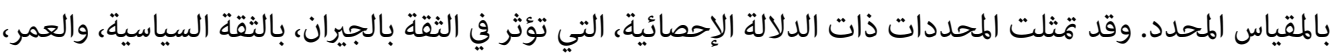
والمتغير المتداخل بين الدين والتدين، في حين مل يكن لمتغيرات اللغة، والنوع الاجتماعي، والدفاع عن حقوق الإنسان،

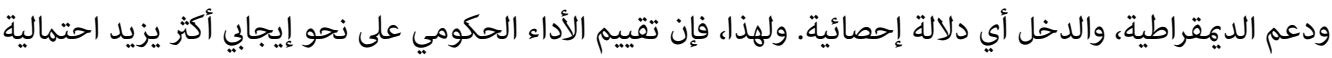

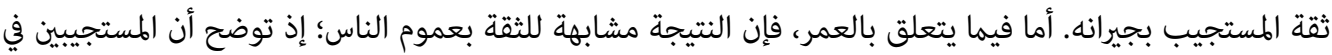

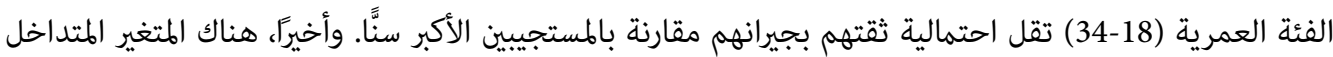

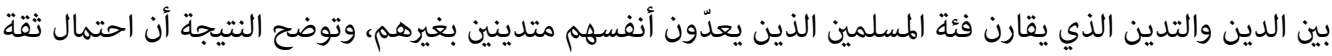
هذه الفئة بجيرانها تزداد مقارنة بغيرها من الفئات بدلالة إحصائية مثبتة عند المستوى 5 في المئة. ويفحص المقياس الثاني محددات الثقة بالأشخاص الذين يعرفهم الُستجيب، ويمكن أن نطلق عليها - تسهيلًا "الثقة بالمعارف". وتوضح النتائج أن محددات هذه الثقة أكثر من الثقة الخاصة بالجيران، وتتمثل محدداتها بالثقة الثة والثة

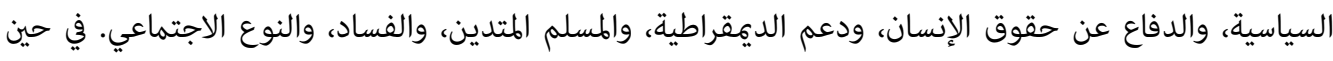

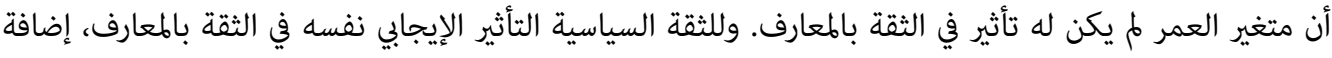

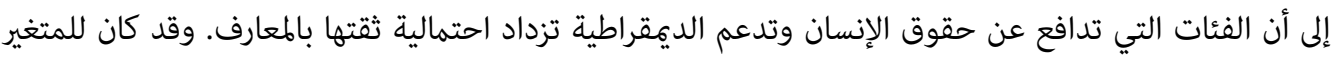
المتداخل بين الدين والتدين، أيضًا، تأثير إيجابي في احتمالية الثقة بالمعان الثان.

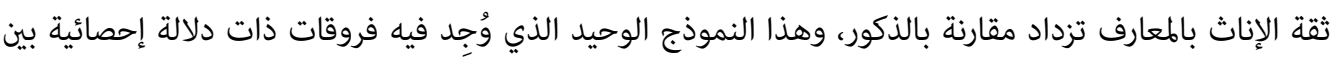

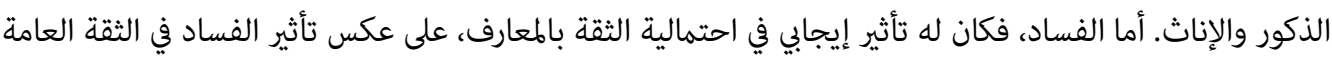

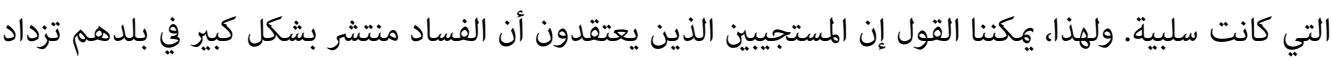
احتمالية ثقتهم بالأشخاص الذين يعرفونهم. ويمكن تفسير هذه النتيجة بأن انتشار الفساد يزيد قدرة استغلال الأفراد لمعارفهم الشخصية في تحقيق مصالحهم أو حمايتها.

ويقيس النموذج 7 محددات الثقة بالمستجيبين الذين التقيت بهم أوّل مرة. وتوضح النتائج أن المتغيرات التي تؤثر

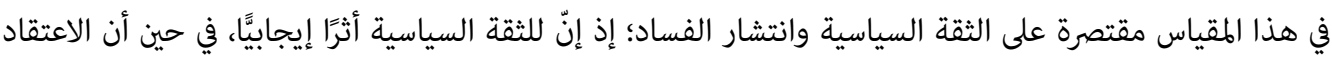

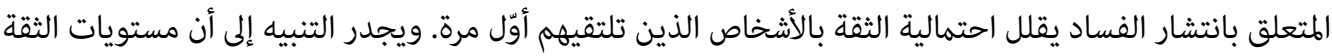

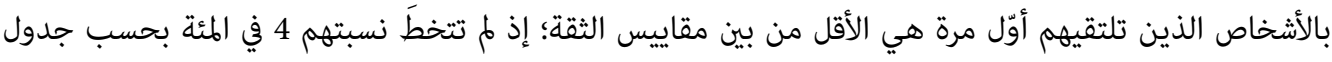
الوصف الإحصائي.

وتتمثل خلاصة النتائج في أن للتحكم في المتغيرات الثابتة (مثل الثقافة) على المستوى المكاني (المحافظة) تأثيرًا واضحًا

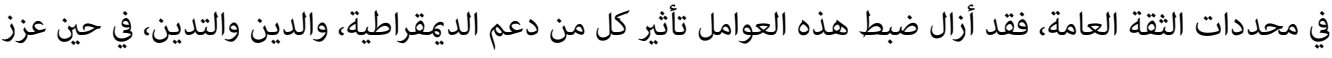
تأثير الدخل في الثقة العامة على مستوى المحافظة نفسها، بكعنى أن المستجيبين ذوي الخصائص الثابتة عبر الزمن

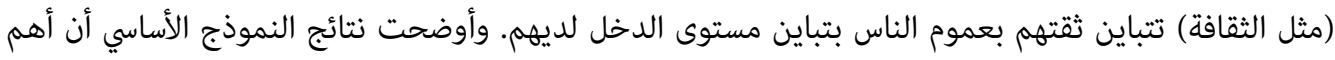

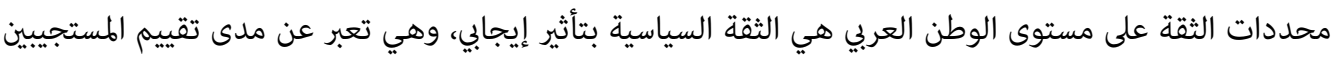

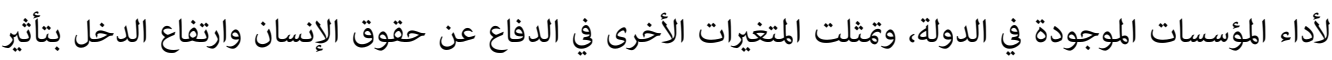


إيجابي في الثقة العامة، في حين أن فئة الشباب وانتشار الفساد واستخدام اللغة غير العربية، بوصفها لغة أولى، كلها محددات لها تأثير سلبي في الثقة العامة. كما تدعم اختبارات الموثوقية النتائج المستخلصة في النموذج الرئيس، خاصة بما يخص تأثير الثقة السياسية الإيجابي في الثقة العامة، إضافة إلى وجود احتمالية أعلى للثقة العامة لفئة الأميين. وفيما يتعلق بالمقاييس الأخرى للثقة، أظهرت النتائج أن أهم محددات الثقة بالجيران تتمثل في الثقة الثانية السياسية

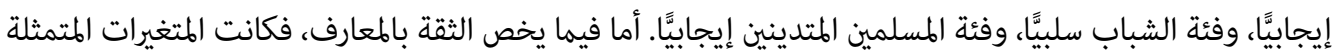

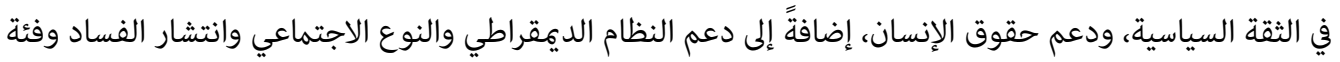

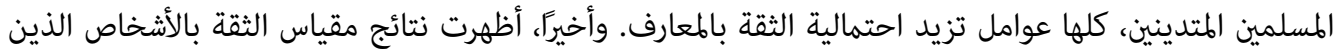

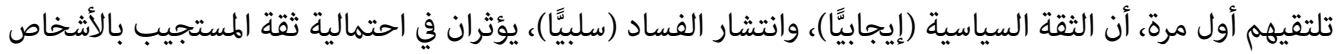
الذين يلتقيهم أول مرة.

\section{خلاصة وتوصيات}

بحثت هذه الدراسة في محددات رأس المال الاجتماعي في الوطن العربي وأثر الأداء السياسي في تعزيز الثقة الاجتماعية، مع استخدام بيانات من فترة زمنية ومصدر مختلف، واستخدام بيانات المؤشر العربي خلال الفترة 2015-2017، وهي تشمل اثنتي عشرة دولة عربية، لضبط المحددات المختلفة التي تؤثر في الثقة العامة للمستجيبين. وبتطبيق هذه البيانات على نهوذج الانحدار اللوجستي، وجدت هذه الدراسة أن تقييم أداء المؤسسات السياسية المقيس من خلئل فلال

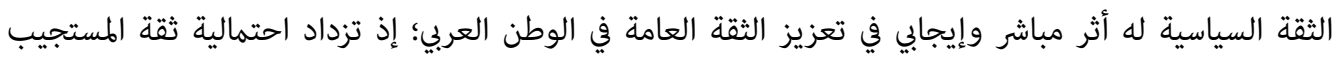

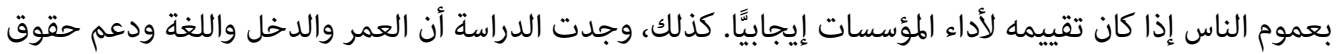
الإنسان والاعتقاد بانتشار الفساد كلها عوامل تؤثر في مستويات الثقة العامة. ووجدت، أيضًا، نتائج مختلفة عن إنات دراسة سبيرنغز التي تعد من أحدث الدراسات العملية التي درست هذا الموضوع على مستوى الوطن العربي (58)؛

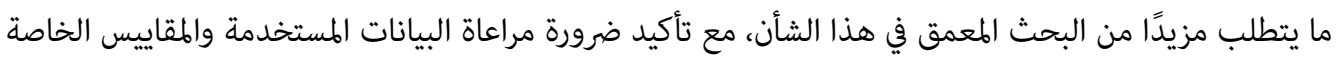
بالمتغيرات المختلفة.

تدعم هذه الدراسة أهمية المؤسسات السياسية في تحديد مستويات الثقة العامة في المجتمع، وتدعم ما أشارت إليه جمال من جهة أن مستويات الثقة العامة المتدنية في الوطن العربي تقلل من شرعية الأنظمة الاستبدادية القائمة

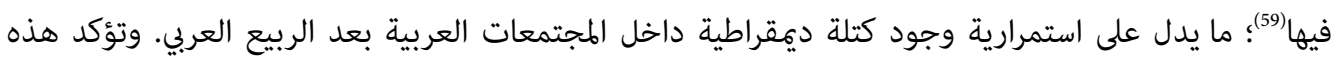

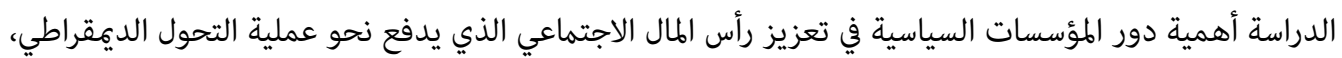
ويسهم في تنمية المجتمعات، وزيادة كفاءة المؤسسات. وفي حال استمرار بقاء الأنظمة العربية من دون توقعات مواطنيها ومتطلباتهم، فإننا نتوقع أن تستمر معدلات الثقة المنخفضة فترةً أطول من فئ الزمن.

وتوصي هذه الدراسة صناع القرار في الوطن العربي بالتفاعل، على نحو أكبر، مع تطلعات المواطنين وتوقعاتهم لتحقيق مستويات ثقة سياسية أعلى؛ الأمر الذي يحسّن من أداء المجتمع، ويزيد من الأعمال الجمعية، ومن ثمّ بـم 
يتطوّر العقد الاجتماعي الحالي. وتؤكد الدراسة وجود ضعف في الثقة العامة بين الشباب، وخاصة في مرحلة ما بعد الربيع العربي؛ ما يؤكد أهمية الارتقاء إلى متطلباتهم وحاجتهم، والدفاع عن مصالحهم واهتماماتهم. وتوصي الدراسة

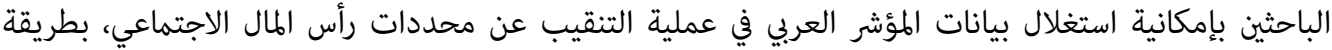

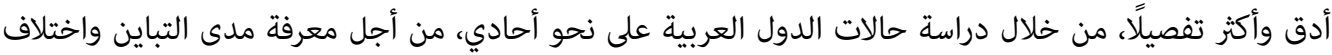

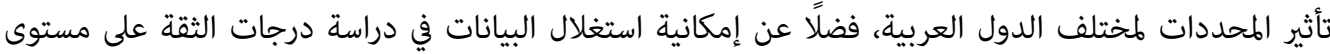
المحافظات، ومدى تأثير الصدمات الاجتماعية والسياسية فيها. كما توصي الدراسة (مع أخذ اختلاف النتائج بين

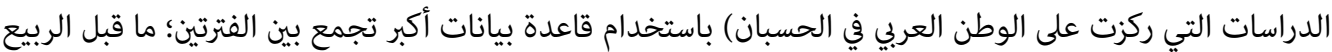
العربي وبعده، وتضمين بيانات من المصادر المختلفة لإعادة البحث في هذه الهحددات وضبط تأثيرها في الثقة العامة. 
بورتيز، أليخاندرو. "رأس المال الاجتماعي: أصوله وتطبيقاته في علم الاجتماع الحديث". ترجمة ثائر ديب. عمران. العدد 27 (شتاء 2019).

\section{الأجنبية}

Ahmed, Ali M. "Are Religious People more Prosocial?: A Quasi-experimental Study with Madrasah Pupils in a Rural Community in India." Journal for the Scientific Study of Religion. vol. 48 , no. 2 (2009).

Alesina, Alberto \& Eliana La Ferrara. "Who Trusts Others?" Journal of Public Economics. vol. 85, no. 2 (2002).

Banfield, Edward C. The Moral Basis of a Backward Society. New York: Free Press, 1958.

Bjørnskov, Christian. "Determinants of Generalized Trust: A Cross-country Comparison." Public Choice. vol. 130, no. 1-2 (2007).

"How Does Social Trust Affect Economic Growth?" Southern Economic Journal. vol.

78, no. 4 (2012).

Chuah, Swee-Hoon, Reema Fahoum \& Robert Hoffmann. "Fractionalization and Trust in India: A Field-experiment." Economics Letters. vol. 119, no. 2 (2013).

Coleman, James S. "Social Capital in the Creation of Human Capital. American Journal of Sociology. vol. 94 (1988).

Cook, K.S. (ed.). Trust in Society. Russell Sage Foundation Series on Trust. New York: Russell Sage Foundation, 2001.

Fish, Steven M. "Islam and Authoritarianism." World Politics. vol. 55 (2002).

Fukuyama, Francis. Trust: The Social Virtues and the Creation of Prosperity. New York: Free press, 1995.

"Social Capital: The Tanner Lectures on Human Values." Brasenose College, Oxford. vol. 12 (1997).

Glaeser, Edward L. et al. "Measuring Trust." The Quarterly Journal of Economics. vol. 115, no. 3 (2000). 
Guiso, Luigi. Paola Sapienza \& Luigi Zingales. "Corporate Culture, Societal Culture, and Institutions." American Economic Review. vol. 105, no. 5 (2015).

Guriev, Sergei \& Nikita Melnikov. "War, Inflation, and Social Capital." American Economic Review. vol. 106, no. 5 (2016).

Haerpfer, Christian et al. (eds.). "World Values Survey: Round Seven- Country-Pooled Datafile." World Values Survey. at: https://cutt.us/GjUVq

Hart, Vivien. Distrust and Democracy: Political Distrust in Britain and America. Cambridge: Cambridge University Press, 1978.

Jamal, Amaney. "When is Social Trust a Desirable Outcome?: Examining Levels of Trust in the Arab World." Comparative Political Studies. vol. 40, no. 11 (2007).

K. Dixit, Avinash. Lawlessness and Economics: Alternative Modes of Governance. Princeton: Princeton University Press, 2011.

Knack, Stephen. "Trust, Associational Life, and Economic Performance." The Contribution of Human and Social Capital to Sustained Economic Growth and well-being (2001).

Knack, Stephen \& Paul J. Zak. "Building Trust: Public Policy, Interpersonal Trust, and Economic Development." Supreme Court Economic Review. vol. 10 (2003).

Levi, Margaret. "Social and Unsocial Capital: A Review Essay of Robert Putnam's Making Democracy Work." Politics \& Society. vol. 24, no. 1 (1996).

Mishler, William \& Richard Rose. "Trust, Distrust and Skepticism: Popular Evaluations of Civil and Political Institutions in Post-communist Societies." The Journal of Politics. vol. 59, no. 2 (1997). Narayan, Deepa. Bonds and Bridges: Social Capital and Poverty. Washington DC: World Bank, 1999. Newton, Kenneth. "Trust, Social Capital, Civil Society, and Democracy." International Political Science Review. vol. 22, no. 2 (2001).

Offe, Claus. "How Can we Trust our Fellow Citizens." Democracy and Trust. vol. 52 (1999).

Pennington, Mark \& Yvonne Rydin. "Researching Social Capital in Local Environmental Policy Contexts." Policy \& Politics. vol. 28, no. 2 (2000).

Putnam, Robert D, Robert Leonardi \& Raffaella Nanetti. Making Democracy Work: Civic Traditions in Modern Italy. Princeton: Princeton University Press, 1993.

Scott, James. Seeing like a State: How Certain Schemes to Improve the Human Condition Have Failed. United States of America: Yale University Press, 2020. 
Spierings, Niels. "Social Trust in the Middle East and North Africa: The Context-Dependent Impact of Citizens' Socio-Economic and Religious Characteristics." European Sociological Review. vol. 35, no. 6 (2019).

Sulemana, Iddisah \& Ibrahim Issifu. "An Empirical Examination of the Determinants of Trust in Ghana." International Journal of Social Economics. vol. 42, no. 11 (2015).

Uslaner, Eric M. "The Foundations of Trust: Macro and Micro." Cambridge Journal of Economics. vol. 32 (2008).

World Bank Group. "PPP Conversion Factor, GDP (LCU per International \$)." accessed on 11/11/2019. at: https://cutt.us/qzNvb 